\title{
État des connaissances sur la ligne de rivage Micmac de J. W.
} Goldthwait (estuaire du Saint-Laurent)

\author{
A Review of the Micmac Shoreline of J. W. Goldthwait (St.
}

Lawrence Estuary)

Estado del conocimiento sobre la línea de ribera Micmac de J.W. Goldthwait (estuario del Saint-Laurent)

\section{Jean-Claude Dionne}

Volume 56, numéro 1, 2002

URI : https://id.erudit.org/iderudit/008607ar

DOI : https://doi.org/10.7202/008607ar

\section{Aller au sommaire du numéro}

\section{Éditeur(s)}

Les Presses de l'Université de Montréal

\section{ISSN}

0705-7199 (imprimé)

1492-143X (numérique)

\section{Découvrir la revue}

\section{Citer cet article}

Dionne, J.-C. (2002). État des connaissances sur la ligne de rivage Micmac de J. W. Goldthwait (estuaire du Saint-Laurent). Géographie physique et Quaternaire, 56(1), 97-121. https://doi.org/10.7202/008607ar

\section{Résumé de l'article}

Caractéristique des rives du Saint-Laurent estuarien, la ligne de rivage Micmac de J. W. Goldthwait (1911) est une notion complexe. Telle que décrite il y a plus de 90 ans, elle comprend trois unités : 1) une falaise morte (falaise Micmac) taillée tantôt dans le substrat rocheux du Cambro-ordovicien pour la rive sud et les îles, tantôt dans des dépôts meubles quaternaires ou holocènes. Sur la rive sud, elle s'étend, presque sans interruption, entre Lévis et Sainte-Anne-des-Monts (Gaspésie). On la retrace aussi à plusieurs endroits sur la rive nord entre Québec et Blanc-Sablon, sur la plupart des îles y compris Anticosti, et dans le secteur du haut estuaire en amont de Québec ; 2) une basse terrasse d'accumulation (terrasse Mitis), de plusieurs dizaines à quelques centaines de mètres de largeur, édifiée au pied de la falaise morte ; 3) une plate-forme intertidale taillée tantôt dans le roc, tantôt dans des matériaux meubles principalement argileux. Ces trois composantes présentent des variations morpho-sédimentologiques d'un endroit à l'autre. La basse terrasse a été datée dans 36 localités réparties sur les deux rives du Saint-Laurent estuarien. La médiane ( $n$-43) est de $2030 \pm 80$ ans BP. À cette époque, le niveau marin relatif était de 3,5 à 4,5 m au-dessus du niveau actuel. La falaise et la plate-forme intertidale taillées dans les formations meubles furent façonnées à deux reprises lors de fluctuations du niveau marin relatif, à l'Holocène supérieur. Quant à la falaise et à la plate-forme rocheuses, il s'agit d'un complexe morphologique ancien, datant au moins du Sangamonien, car des marques glaciaires sur la plate-forme ainsi que des dépôts wisconsiniens confirment l'existence de la surface rocheuse avant le passage du dernier glacier.
Tous droits réservés @ Les Presses de l'Université de Montréal, 2002
Ce document est protégé par la loi sur le droit d'auteur. L'utilisation des services d’Érudit (y compris la reproduction) est assujettie à sa politique d'utilisation que vous pouvez consulter en ligne.

https://apropos.erudit.org/fr/usagers/politique-dutilisation/ 


\section{ÉTAT DES CONNAISSANCES SUR LA LIGNE DE RIVAGE MICMAC DE J.W. GOLDTHWAIT (ESTUAIRE DU SAINT-LAURENT)}

Jean-Claude DIONNE, Département de géographie et Centre d'études nordiques, Université Laval, Québec, Québec G1K 7P4.

RÉSUMÉ Caractéristique des rives du SaintLaurent estuarien, la ligne de rivage Micmac de J. W. Goldthwait (1911) est une notion complexe. Telle que décrite il y a plus de 90 ans, elle comprend trois unités : 1) une falaise morte (falaise Micmac) taillée tantôt dans le substrat rocheux du Cambro-ordovicien pour la rive sud et les îles, tantôt dans des dépôts meubles quaternaires ou holocènes. Sur la rive sud, elle s'étend, presque sans interruption, entre Lévis et Sainte-Annedes-Monts (Gaspésie). On la retrace aussi à plusieurs endroits sur la rive nord entre Québec et Blanc-Sablon, sur la plupart des îles y compris Anticosti, et dans le secteur du haut estuaire en amont de Québec ; 2) une basse terrasse d'accumulation (terrasse Mitis), de plusieurs dizaines à quelques centaines de mètres de largeur, édifiée au pied de la falaise morte ; 3 ) une plate-forme intertidale taillée tantôt dans le roc, tantôt dans des matériaux meubles principalement argileux. Ces trois composantes présentent des variations morpho-sédimentologiques d'un endroit à l'autre. La basse terrasse a été datée dans 36 localités réparties sur les deux rives du Saint-Laurent estuarien. La médiane $(n-43)$ est de $2030 \pm 80$ ans BP. À cette époque, le niveau marin relatif était de 3,5 à 4,5 m au-dessus du niveau actuel. La falaise et la plate-forme intertidale taillées dans les formations meubles furent façonnées à deux reprises lors de fluctuations du niveau marin relatif, à l'Holocène supérieur. Quant à la falaise et à la plate-forme rocheuses, il s'agit d'un complexe morphologique ancien, datant au moins du Sangamonien, car des marques glaciaires sur la plate-forme ainsi que des dépôts wisconsiniens confirment l'existence de la surface rocheuse avant le passage du dernier glacier.
ABSTRACT A review of the Micmac shoreline of J. W. Goldthwait (St. Lawrence estuary). The Micmac shoreline of Goldthwait (1911) is a complex feature common to both shores of the St. Lawrence estuary. As described 90 years ago, the Micmac shoreline is composed of three units: 1) a former cliff (Micmac cliff) cut into Cambro-ordovician bedrock for the south shore and islands, and/or in Quaternary/Holocene unconsolidated deposits, which extends most continuously from Lévis to Sainte-Anne-des-Monts on the south shore; it occurs also at many localities on the north shore between Québec City and Blanc-Sablon, on most islands including Anticosti, and in the upper St. Lawrence estuary; 2) a low accretion terrace (Mitis terrace), a few hundred meters wide, built at the foot of the cliff; 3) an intertidal shore platform cut alternatively in shales or slates or in Quaternary unconsolidated deposits. In addition, these units present many morpho-sedimentological aspects from place to place. The low terrace has been radiocarbon dated in 36 localities from both shores of the St. Lawrence estuary. The median age $(n-43)$ is $2030 \pm 80$ years BP. At that time the relative sea level (RSL) was 3.5 to $4.5 \mathrm{~m}$ above present day. The cliff and the adjacent intertidal platform cut into unconsolidated deposits, are undoubtedly mid- to late- Holocene erosional features formed during two episodes of RSL fluctuations. The rock cliff and related shore platform are inherited features of Sangamonian age or older which have been slightly modified by glacial and shore processes during the Wisconsin and the Holocene. At many sites, glacial erosion features have been preserved on the shore platform whereas at a few localities the platform is partially covered by Wisconsinan deposits, giving evidence of its existence before the last glaciation.
RESUMEN Estado del conocimiento sobre la línea de ribera Micmac de J.W. Goldthwait (estuario del Saint-Laurent). Aunque característica de las riberas del estuario del SaintLaurent, la línea de ribera Micmac de J. W. Goldthwait (1911) es una noción compleja. Siguiendo la descripción hecha hace mas de 90 años, dicha formación comprende tres unidades: 1) Un acantilado muerto (acantilado Micmac) edificado en parte por un substrato rocoso que data del Cambrico-ordovícico del lado de la ribera sur y de las islas, y en parte por depósitos poco consolidados que datan del cuaternario o del holoceno. Del lado de la ribera sur se extiende casi sin interrupción entre Lévis y Sainte-Anne-des-Monts (Gaspésie). Puede localizarse también en varios sitios en la ribera norte entre Québec y Blanc-Sablon en la mayoría de las islas incluyendo Anticosti, y en el sector de la parte alta del estuario río arriba de Québec;2) Una terraza baja de acumulación (terraza Mitis), de varias decenas a centenas de extensión, edificada al pie del acantilado. 3) Una plataforma intermareal tallada en parte en roca, en parte formada de materiales no consolidados principalmente arcillosos. Estos tres compuestos presentan variaciones morfológicas y sedimentológicas de un sitio a otro. La terraza baja a sido datada a lo largo de sus 36 localidades repartidas en las dos riberas del estuario del Saint-Laurent. La mediana (n-43) es de $2030 \pm 80$ años BP. En esa época el nivel relativo del mar era de 3,5 a $4,5 \mathrm{~m}$ por encima del nivel actual. El acantilado y la plataforma intermareal tallada en las formaciones fue trazada en dos ocasiones a lo largo de las fluctuaciones del nivel relativo del mar durante el holoceno superior. En conjunto el acantilado y la plataforma rocosa forman un complejo geomorfológico antiguo que data del periodo de Eemien o quizás mas antiguo ya que las marcas de glaciación en la plataforma así como de los depósitos winsconsinianos confirman la existencia de una superficie rocosa anterior a la ultima glaciación. 


\section{INTRODUCTION}

Signalée pour la première fois dans la littérature scientifique il y a 140 ans (Logan, 1863), la ligne de rivage Micmac n'a pas encore révélé tous ses secrets. Si plusieurs l'ont évoquée ou en ont brièvement parlé, peu l'ont vraiment étudiée en dehors de J. W. Goldthwait (1911a). Le temps semble venu de faire la synthèse des connaissances sur un sujet assez complexe qui, encore de nos jours, est source fréquente de confusion.

La ligne de rivage Micmac de Goldthwait et ses composantes constituent un élément majeur du littoral du SaintLaurent estuarien, voire même de certains secteurs du golfe. Les données acquises au cours des dernières décennies permettent maintenant de comprendre et d'expliquer d'une façon plus satisfaisante cette importante ligne de rivage et de dater les événements géologiques survenus dans le passé. Après que les principaux travaux consacrés au sujet aient été rappelés, la terminologie et la dénomination des formes seront examinées brièvement afin de clarifier une appellation ambiguë qui a entraîné certaines dérives; puis les caractéristiques des éléments constituant cette ligne de rivage seront exposées avant d'expliquer l'origine et de préciser l'âge de ses diverses composantes.

\section{TRAVAUX ANTÉRIEURS}

\section{LA PÉRIODE ANTÉRIEURE À 1960}

Dans cette mise à jour des connaissances, il convient de rappeler d'abord ce que divers auteurs entendent par la ligne de rivage Micmac.

Logan (1863, p. 921) parle de " $A$ low terrace, about five feet above the highest tides, and averaging about 100 yards in breath, extends, with a few interruptions, from Rimouski to Whale Cape, a distance of seventy-five miles. It is composed of sand, gravel, and broken shells, and makes a good roadway, as well as a productive soil. The shells in this terrace are of the same species as now inhabit the adjacent water. Besides these, bones of whale and the morse have been found partially imbedded in this deposit, in several places between Bic and Matane. »

Bien que cette basse terrasse ne soit pas nommée, il s'agit bien de la terrasse Micmac de Goldthwait, une forme littorale caractéristique de la rive sud de l'estuaire du Saint-Laurent (fig. 1) mentionnée par Dawson (1893) dans son ouvrage The Canadian Ice Age.

Goldthwait (1911a, 1911b, 1913) fut le premier et l'un des seuls à s'intéresser sérieusement à cette basse terrasse et à la falaise qui y est associée. Son article de 1911, paru dans l'American Journal of Science, constitue un travail d'envergure inégalée compte tenu des conditions de l'époque. Malgré l'absence de cartes topographiques et géologiques à moyenne et à grande échelles, de cartes des formations meubles, de photographies aériennes, de méthodes de datation, d'une part, et en raison de travaux de terrain très restreints et de l'état limité des connaissances en Quaternaire au début du $X X^{e}$ siècle, d'autre part, Goldthwait a produit un article d'une rare qualité qu'il importe de connaître.

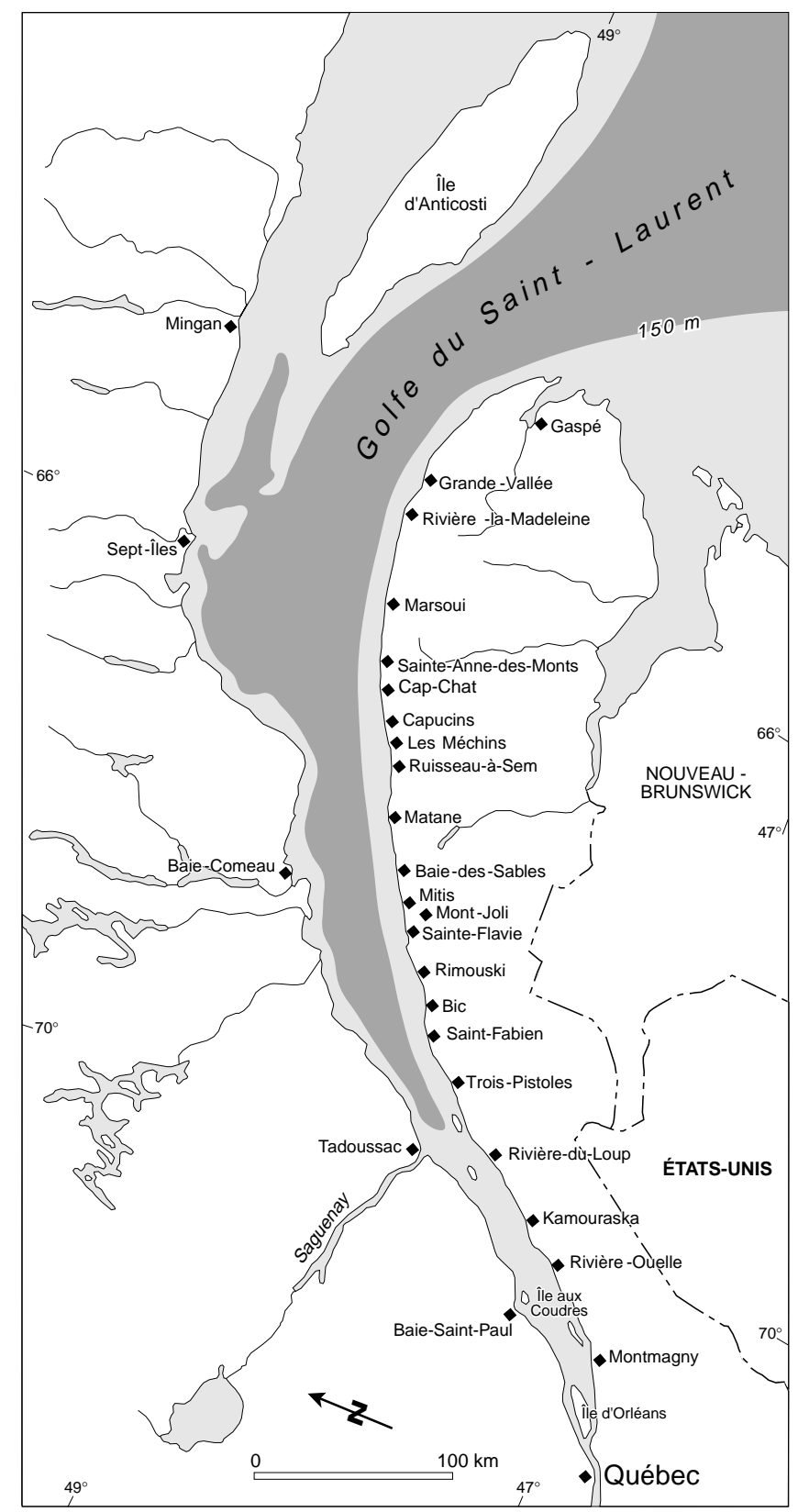

FIGURE 1. Carte de l'estuaire du Saint-Laurent. Localisation des principaux noms de lieu, de Québec à l'île d'Anticosti.

Location map of the St. Lawrence estuary between Québec City and Île d'Anticosti with main localities mentioned in text.

Pour Goldthwait (1911a), la ligne de rivage Micmac comprend la basse terrasse déjà signalée par Logan (1863), une falaise morte et une plate-forme rocheuse. Ces différents éléments de la géomorphologie littorale du Saint-Laurent estuarien ont été façonnés au cours de l'Holocène, durant une période de stabilité relativement longue caractérisant l'émersion postglaciaire des terres. La falaise Micmac est en grande partie taillée dans des formations rocheuses consolidées (principalement des schistes tendres) et dans du «drift 
glaciaire »'1. Attribuée à l'action des vagues et des courants, l'érosion pose problème dans la région de Québec car, à cet endroit très étroit du Saint-Laurent, la plate-forme rocheuse est beaucoup plus large et la falaise morte, plus haute qu'en aval, c'est-à-dire là où le rivage est plus exposé aux agents d'érosion caractéristiques des milieux littoraux. Goldthwait (1911a) évoque aussi la possibilité d'une phase de subsidence. II écrit (p. 311) : «It will be noticed that if the Micmac sea-cliff was cut back during a stage of slow coastal submergence, a record of this submergence might be left, in protected reentrants, in the form of forest beds buried by the advancing gravels and sands of the beach, and subsequently raised, with the overlying material, above high-tide mark; in other words, stumps and fresh-water peat might be discovered beneath the marine sands on the Micmac terrace. "

Dans son ouvrage, The New England-Acadian Shoreline, Johnson (1925, p. 223-234) a repris le sujet en se basant en grande partie sur l'article de Goldthwait, sur l'examen de la Canadian Naval Service Chart $n^{\circ} 204$, et sur ses observations lors d'une brève visite du terrain dans la région de Québec et du Bas-Saint-Laurent (Goldthwait, 1913). Si cette contribution ajoute peu de données de terrain aux connaissances, elle permet par contre une utile discussion de certains aspects signalés par Goldthwait et appuie l'hypothèse de l'ancienneté du relief rocheux attribuable à un aplanissement subaérien sous un régime fluviatile. Pour Johnson, les grandes surfaces relativement planes de la zone côtière (plate-forme submergée), entre TroisPistoles et Bic, sont d'anciennes surfaces rocheuses aplanies par érosion subaérienne. On sait aujourd'hui, grâce à des sondages sismiques (B. Long, 1999, communication personnelle) que la partie interne du plateau continental dans ce secteur est constituée d'épais dépôts meubles quaternaires qui recouvrent un substrat rocheux irrégulier formé de crêtes et de dépressions. II ne s'agit donc pas d'un plateau rocheux aplani comme le pensait Johnson. Cette grande surface que Johnson, à la suite de Goldthwait, inclut dans la ligne de rivage Micmac doit donc être reconsidérée et réinterprétée.

Dans un rapport manuscrit, The St. Lawrence Lowland ${ }^{2}$, Goldthwait (1933, p. 123-145a) a repris le sujet de la ligne de rivage Micmac et ajouté de nouvelles données recueillies sur le terrain en 1926, dans le secteur entre Kamouraska et Québec, sur la côte de Beaupré ainsi que sur l'île d'Orléans. L'auteur (p. 145) attribue un rôle important aux glaces dans l'érosion de la plate-forme littorale particulièrement large dans la région de Québec. II mentionne aussi que 1) «The Micmac shoreline is restricted to the St. Lawrence»;2) « The last emergence was an uplift of land and not a lowering of the sea»;3) «The Micmac stage was another interval of crustal stability interrupting the upwarping ; 4) «The Micmac halt was by far the longest of all that came during or after the Champlain marine submergence».

1. Au début du dernier siècle, les géologues appelaient «boulder clay», l'argile caillouteuse de la Mer de Goldthwait, d'où l'expression «glacial drift» utilisée par Goldthwait. En général, en Angleterre, le «boulder clay » correspond à du till ou à un diamicton glacio-marin. Cette expression n'est plus utilisée de nos jours (Dionne, 1970, p. 189-191).

2. On trouve des extraits de ce document dans Gadd (1971, p. 115-146).
En conclusion, Goldthwait (1933) affirme que « The Micmac shelf and seacliff register a long stage of crustal stability, during which it is thought batture ice played a very important role in cutting a watermark ». Pour l'auteur, la ligne de rivage Micmac « register a 20-foot uplift, confined more or less to the QuébecGaspé district ». II ajoute que le soulèvement est très récent et qu'il faudrait prendre en considération le caractère sismique du Saint-Laurent estuarien qui aurait pu jouer un rôle dans l'édification de la ligne de rivage Micmac.

Blanchard (1935, p. 126) a accordé peu d'attention à la ligne de rivage Micmac. Après un exposé général succinct sur les terrasses côtières du Bas-Saint-Laurent, il conclut ainsi son argumentation : "Ainsi disparaît l'étrange conception de la "terrasse de 20 pieds" que Goldthwait veut voir tout le long de l'estuaire ; fréquemment elle est formée de bas talus coalescents de débris descendus des falaises en arrière, et parfois de la partie émergée de plages rocheuses; aussi l'altitude et la largeur de cette prétendue terrasse sont-elles des plus variables. » L'opinion de Blanchard reflète une connaissance superficielle du sujet.

Dans un article consacré à la chronologie de l'Holocène dans le nord-est de l'Amérique du Nord, Lougee (1953, p. 274) parle de la Micmac Sea. Du point de vue chronologique, la stabilité Micmac constitue le deuxième événement important depuis la déglaciation. Cet événement serait antérieur à l'émersion de la vallée du Saint-Laurent et à l'optimum climatique que l'on date généralement de l'Holocène moyen (Deevy et Flint, 1957). II écrit que la terrasse Micmac sur la rive nord du Saint-Laurent estuarien atteint une altitude excédant parfois $13 \mathrm{~m}$. La différence d'altitude par rapport à la rive sud est attribuée à une ligne charnière (Algonquin hinge line) séparant les deux rives de l'estuaire.

Le sujet a été repris dans une publication parue après la mort de l'auteur (Lougee et Lougee, 1976, p. 72-73, 330-333 et 442). Dans cette publication, Richard Lougee (p. 333) reconnaît que "The climatic optimum may be related in time to the Micmac stability». II écrit que «The Micmac terrace is an unusually strong landscape feature, resulting from a combination of crustal stability and a sea level that, presumably, was rising slowly at the time of its development ». Sur la Côte Nord, "The Micmac terrace stands at 40 to 45 feet above sea level at Baie Ste. Catherine». À cet endroit la terrasse Micmac daterait de $3,1 \mathrm{ka}(3150 \pm 130 \mathrm{BP})^{3}$.

McGerrigle (1954, p. 19-20) signale aussi l'existence de la terrasse Micmac en Gaspésie : «La plus basse et, sans doute la plus récente, est une terrasse coupée dans le roc, correspondant aux plaines côtières existantes et, pour la plus grande partie, s'adossant du côté des terres sur une falaise marine. C'est le prolongement de la ligne de rivage Micmac. La ligne de rivage Micmac et la marque de haute marée de la

3. Il s'agit de la plus ancienne date au radiocarbone au Québec réalisée dans un laboratoire, à l'Université du Manitoba, au début des années 1950. Malheureusement, nous ignorons le numéro de laboratoire. La date a été obtenue sur un morceau de bois dans une unité sableuse entre 9 et $11 \mathrm{~m}$ d'altitude de la terrasse de 12-13 m (plages) recouverte de 1,5 m de sable éolien (Lougee et Lougee, 1976, p. 334). 
ligne actuelle de rivage coïncident presque, et toutes deux sont relativement droites. " L'auteur s'étonne du fait «que le plan Micmac demeure si constant sur une distance d'au moins 300 milles » et aussi que la «la ligne de rivage Micmac soit la seule dont on peut faire la corrélation latéralement sur une certaine distance ».

\section{LA PÉRIODE POSTÉRIEURE À 1960}

S'il existe plusieurs travaux postérieurs à 1960 faisant référence (tabl. I) à la ligne de rivage Micmac, sauf pour certains (Dionne, 1963, 1996a, 1996b ; Locat, 1976; Bélanger, 1993), la plupart sont laconiques et ne font pas le tour de la question.

Dionne (1963) semble le premier à avoir reconnu la complexité de la ligne de rivage Micmac et à en distinguer les trois principales composantes : 1) une falaise morte taillée tantôt dans le roc, tantôt dans des formations meubles et tantôt dans les deux (falaise Micmac) ; 2) une basse terrasse meuble au pied de la falaise morte (terrasse Mitis) ; 3) une plate-forme

\section{TABLEAU I}

Liste des auteurs faisant référence à la ligne de rivage Micmac (par ordre chronologique)

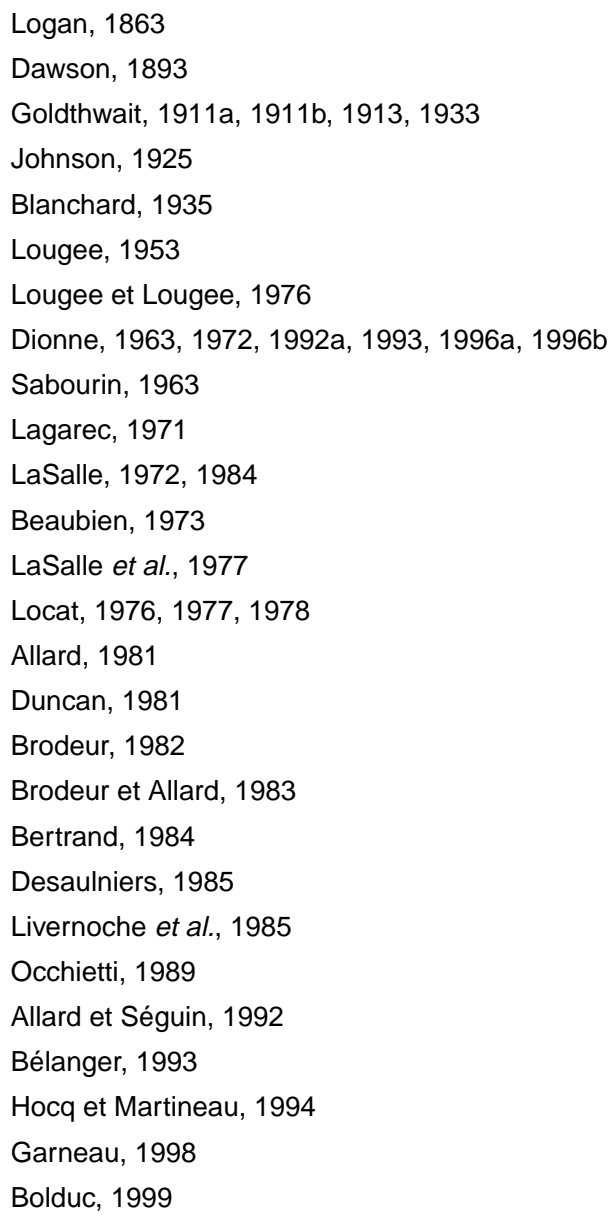

Bolduc, 1999

intertidale (batture) meuble ou rocheuse (terrasse Rimouski). Bien que ces différents éléments du relief littoral ne soient pas datés d'une façon précise, l'auteur reconnaît le caractère ancien de la falaise et de la plate-forme rocheuse à son pied ainsi que la formation postérieure de la terrasse Mitis (Dionne, 1972, p. 34-38).

Locat $(1976$, p. $28-36 ; 1977$, p. $300 ; 1978$, p. $10-12$ ) a consacré quelques pages aux terrasses marines du Bas-SaintLaurent y compris la ligne de rivage Micmac, et il a reconnu les trois unités distinguées par Dionne (1963). Dans un souci de plus grande clarté, il a appelé "surface de Micmac », la plateforme rocheuse et la falaise morte associée et il a proposé une nouvelle appellation pour la terrasse Mitis et la terrasse Micmac de Dionne, renommées respectivement «terrasse de Sainte-Flavie » et «terrasse de Bic» (Locat, 1976, p. 30-31). Dans son article de 1977, Locat donne plutôt aux trois niveaux les noms de Rimouski, Mitis et Bic. Ainsi, la falaise Micmac de Goldthwait devient le talus frontal de la troisième terrasse dénommée Bic. La basse terrasse et la falaise Micmac de Goldthwait n'existent plus comme tels. La "surface de Micmac » désigne alors la plate-forme et la falaise rocheuse. L'auteur fournit une date au ${ }^{14} \mathrm{C}$ de $2240 \pm 140 \mathrm{BP}$ (QU-265) pour la basse terrasse (plages sablo-graveleuses sur la plateforme rocheuse), à Baie-des-Sables, qui corrobore les dates obtenues antérieurement par Lebuis dans la région de Matane $(2260 \pm 110$ BP : QU-152; $2380 \pm 90$ BP : QU-146) (Dionne, 1977).

Bélanger (1993) a fait un relevé exhaustif de la ligne de rivage Micmac entre Montmagny et Trois-Pistoles. Le document contient un nombre impressionnant de données et une description détaillée de l'ensemble de la côte subdivisée en douze secteurs. On y trouve plusieurs profils transversaux morpho-sédimentologiques avec des références altimétriques précises ainsi que des profils verticaux des terrasses et de la zone intertidale. L'auteur (p. 216-219) a rassemblé les dates au radiocarbone disponibles à l'époque, dont plusieurs obtenues dans le cadre de cette première étude exhaustive. II a aussi proposé une série de fluctuations du niveau marin relatif au cours de l'Holocène (Bélanger, 1993, p. 223) susceptible d'expliquer les diverses composantes de la ligne de rivage Micmac. Par la suite, Dionne (1996a, 1996b) a, de son côté, produit une étude détaillée de la terrasse Mitis à Petite-Rivière et à la pointe aux Alouettes, sur la côte de Charlevoix.

Parmi les autres publications faisant référence à la ligne de rivage Micmac, il convient de mentionner ceux qui considèrent la terrasse Micmac uniquement comme une plateforme rocheuse ancienne, vraisemblablement taillée au cours du dernier interglaciaire (Sangamonien) voire même au Tertiaire (LaSalle, 1972, 1984, 1987 ; LaSalle et al., 1977; Occhietti, 1989; Hocq et Martineau, 1994).

Pour LaSalle (1972, p. 11 et 1987, p. 11), «La terrasse Micmac est une caractéristique morphologique importante dans la région. C'est une plate-forme rocheuse que l'on peut facilement observer entre Québec et Beaupré, sur la rive nord, à environ $30 \mathrm{~km}$ (15 milles) à l'est de Québec. La terrasse se manifeste très bien aussi sur la rive sud, le long de la côte gaspésienne et autour de l'île d'Anticosti. Dans la région de Québec et en plusieurs autres endroits, la terrasse est recouverte soit 
par des sédiments glaciaires, soit par des sédiments marins ou fluviatiles (...) sa formation est certainement antérieure à la dernière avancée glaciaire puisqu'elle est recouverte par des sédiments glaciaires de Gentilly et des varves du lac Deschaillons, qu'on retrouve dans la région de Sainte-Annede-Beaupré. Le développement de cette plate-forme rocheuse est présumément (sic) reliée à un niveau marin élevé lors de l'interglaciaire sangamonien (d'où les dépôts de Saint-Pierre sont possiblement issus). 》

Dans LaSalle et al. (1977, p. 3-4), la ligne de rivage Micmac est décrite en ces termes : “Ces deux accidents géomorphologiques (la terrasse et l'escarpement) ne sont pas taillés dans du drift glaciaire, du moins pas de façon continue, comme l'affirmait Goldthwait (1911[a], p. 296). C'est plutôt l'inverse qui est vrai. Pour la plus grande partie de la distance entre Québec et Sainte-Anne-de-Beaupré, l'escarpement Micmac est taillé dans le roc et la plate-forme rocheuse sousjacente ( $\mathrm{sic}$ ) est recouverte de sédiments meubles, généralement des sédiments estuariens du proto-Saint-Laurent, ainsi que par endroits, de sédiments glaciaires (till et dépôts fluvioglaciaires) ou interglaciaires. L'érosion de la plate-forme rocheuse de Micmac et de l'escarpement qui l'accompagne n'est donc pas relié à une érosion post-glaciaire mais bien à l'action ancienne d'agents géologiques qui peuvent être multiples. On doit associer cette terrasse à une érosion interglaciaire (Quaternaire) ou pré-glaciaire (Tertiaire). »

On retrouve la même interprétation dans Occhietti (1989, p. 392) : «La terrasse (Micmac) est mise en corrélation avec la plate-forme d'abrasion littorale observée dans les provinces atlantiques et attribuée au dernier interglaciaire, celui du Sangamonien. Elle implique une érosion littorale active associée à un niveau eustatique d'environ $6 \mathrm{~m}$ plus haut que l'actuel (...); aux environs de Québec, elle est sous-jacente aux rythmites qui reposent sous les sédiments attribués à l'intervalle de Saint-Pierre. »

Pour Hocq et Martineau (1994, p. 123), «la terrasse Micmac, en aval de Québec sur la côte de Beaupré et sur l'île d'Orléans, et son équivalent sur l'île d'Anticosti seraient vraisemblablement des reliques de l'érosion préwisconsinienne et possiblement d'âge Tertiaire ».

On trouve aussi d'autres données partielles sur la ligne de rivage Micmac dans Sabourin (1963) pour la côte de Beaupré, Lagarec 1971) et Allard et Séguin (1992) pour la région de Québec; Beaubien (1973) et Allard (1981) pour l'île d'Orléans; Brodeur (1982) et Brodeur et Allard (1983) pour l'île aux Coudres; Desaulniers (1985) pour le secteur entre Donnacona et Cap-Rouge ; Duncan (1981) pour le secteur entre La Pocatière et Saint-Denis-de-Kamouraska; Livernoche et al. (1985), Gray, édit (1987) et Hétu et Gray (2000) pour la côte nord de la Gaspésie; Bertrand (1984) et Garneau (1987) pour le secteur de Cacouna - Isle-Verte, et Hétu (1994) pour la région de Rimouski. Récemment, Bolduc (1999) a signalé l'existence de la terrasse Mitis dans la région de Champlain sur la rive nord du haut estuaire et obtenu une date $a{ }^{14} \mathrm{C}$ de 2,1 ka.

Bref, s'il existe de nombreuses références à la ligne de rivage Micmac, la synthèse des connaissances restait à faire. C'est l'objet de la présente contribution.

\section{QU'EST-CE QUE LA LIGNE DE RIVAGE MICMAC?}

La ligne de rivage Micmac est une notion complexe qui a entraîné beaucoup de confusion. Selon Goldthwait (1911a), elle comprend plusieurs éléments. D'abord une basse terrasse relativement étroite, construite de sable et gravier stratifiés (plages) reposant sur un substrat rocheux au pied d'une falaise morte généralement rocheuse. II s'agit de la basse terrasse signalée par Logan (1863), forme prédominante du littoral entre Rimouski et Sainte-Anne-des-Monts. Dans d'autres secteurs, la basse terrasse est plutôt formée d'alluvions fines (dépôts intertidaux) ou d'argile comme à L'Isle-Verte et Kamouraska. Elle est souvent beaucoup plus large et s'étend généralement dans ce cas au pied d'une falaise morte taillée dans «l'argile à blocaux ». Goldthwait (1911a, p. 305) a appelé la basse terrasse en bordure du rivage actuel, «terrasse Micmac » en l'honneur des Amérindiens de la péninsule gaspésienne et du Nouveau-Brunswick adjacent.

Fait aussi partie de la ligne de rivage Micmac, un escarpement d'érosion très net, de plusieurs mètres de hauteur, sis à l'arrière de la basse terrasse, que Goldthwait a aussi appelé «falaise Micmac. » Pour Goldthwait, la falaise morte est tantôt rocheuse, tantôt taillée dans du drift glaciaire. À cet escarpement rocheux est associée une plate-forme d'érosion qui forme le substrat de la terrasse Micmac, là où elle est constituée de plages sablo-graveleuses, et qui affleure un peu partout dans la zone intertidale actuelle.

Le bas estran ou la batture argileuse, particulièrement large dans la région de Trois-Pistoles, de L'Isle-Verte et de Kamouraska, constitue une autre composante de la ligne de rivage Micmac. Goldthwait inclut aussi la surface plane adjacente à la zone infratidale ou pré-littorale (submerged platform) qui s'étend vers le large jusqu'à trois brasses $(6 \mathrm{~m})$ de profondeur par rapport à la limite des basses mers.

La zonation verticale de la ligne de rivage Micmac de Goldthwait a donc une amplitude d'environ 15 m et est composée de cinq éléments qui n'ont pas forcément le même âge, la même nature ni la même signification. II paraît difficile alors de déterminer un niveau de rivage précis quand les diverses composantes de la ligne de rivage Micmac sont confondues. Il apparaît donc essentiel de caractériser les trois principales composantes de la ligne de rivage Micmac pour comprendre les faits et les expliquer. Mais avant de caractériser les diverses composantes du rivage, il importe de préciser la terminologie, c'est-à-dire la notion de terrasse.

\section{DÉNOMINATION DE LA TERRASSE ET DE LA FALAISE MICMAC}

Goldthwait (1911a) a donné le nom de Micmac à la basse terrasse, à la plate-forme et à la falaise morte à l'arrière. Si au début du siècle dernier, la notion de terrasse n'avait pas encore été correctement définie, ce n'est plus le cas de nos jours. Tous les manuels et les dictionnaires spécialisés définissent une terrasse comme une surface relativement plane et horizontale délimitée à son front par un talus.

Le talus Micmac se trouvant à l'arrière de la basse terrasse appartient donc à la terrasse au-dessus. Dans ce cas, la 

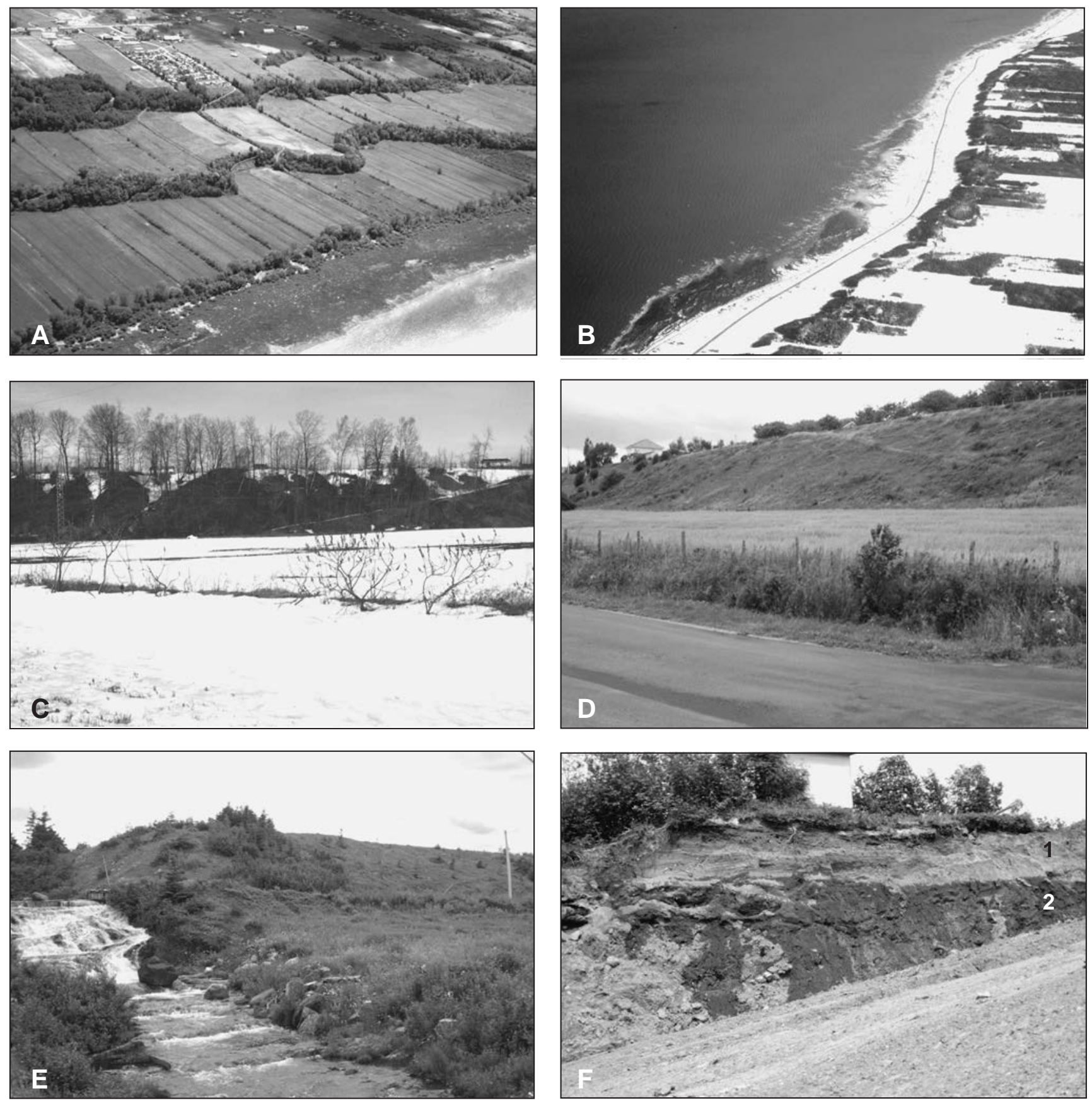

terrasse devrait porter le nom du talus frontal. Or, ce n'est pas le cas, puisque Goldthwait considère la basse terrasse comme la Micmac. Dans un tel cas, comment éliminer la confusion? À notre avis, la falaise morte constitue l'élément morphologique dominant le paysage littoral du Saint-Laurent estuarien; il apparaît alors préférable de conserver l'appellation Micmac pour la falaise morte et, en conséquence, la terrasse associée, c'est-à-dire celle au sommet de l'escarpement (fig. 2a). Nous avons donc proposé le nom de Mitis pour la basse terrasse et le nom de Rimouski pour la surface intertidale actuelle (Dionne, 1963). La plupart des auteurs se sont ralliés à

notre suggestion, alors que certains ont préféré d'autres dénominations (Locat, 1976, 1977 ; Duncan, 1981; Brodeur, 1982).

\section{CARACTÉRISTIQUES DES COMPOSANTES DE LA LIGNE DE RIVAGE MICMAC}

Une bonne connaissance des caractéristiques des trois composantes de la ligne de rivage Micmac de Goldthwait paraît indispensable à la compréhension du sujet (voir Annexe). 
$\leftarrow$ FIGURE 2A. Vue aérienne oblique de la ligne de rivage Micmac sur la rive nord de l'île d'Orléans. On distingue nettement une partie de la batture, la basse terrasse (Mitis), la falaise et la terrasse Micmac, ainsi qu'une quatrième terrasse; les diverses terrasses et les escarpements sont taillés dans le substrat rocheux (schistes du Cambroordovicien) (5.6.89).

B. Vue aérienne oblique, en hiver, de la ligne de rivage Micmac dans le secteur entre Sainte-Luce-sur-Mer et Sainte-Flavie. On voit la falaise morte (Micmac), une basse terrasse relativement étroite et une plate-forme rocheuse dans la zone intertidale. La partie supérieure de la falaise est argileuse alors que la base est rocheuse (schistes). La terrasse Mitis comprend un à trois mètres de sable et de gravier (plages) reposant sur une ancienne plate-forme rocheuse (21.3.91).

C. Falaise Micmac et terrasse Mitis à Neuville, dans le haut estuaire du Saint-Laurent. Entièrement rocheuse, la falaise mesure environ $15 \mathrm{~m}$ de hauteur. La terrasse Mitis à son pied est composée de petits fragments de schistes (plages) de un à deux mètres d'épaisseur, reposant sur une plate-forme rocheuse (schistes) qui affleure dans la zone intertidale et forme à peu près la moitié de la batture (8. 4. 89).

D. Falaise Micmac et terrasse Mitis sur la rive sud de l'île aux Coudres. La falaise rocheuse est parfois coiffée d'un mince dépôt de sable et gravier (plages). Très étroite, la terrasse Mitis, sise au pied de la falaise morte, est composée de sable et de gravier (plages) d'environ un mètre d'épaisseur, reposant sur une surface rocheuse qui forme la partie supérieure de la batture (20.8. 86).

E. Dans le secteur de la rivière Tartigou (entre Baie-des-Sables et Rivière-Blanche), la falaise Micmac est composée d'argile caillouteuse (diamicton) coiffant une crête rocheuse (schistes). A cet endroit, la terrasse Mitis correspond à une surface rocheuse recouverte de un à deux mètres de sable et gravier (plages) (22. 7. 92).

F. Coupe dans la falaise Micmac à Pointe-au-Père montrant un dépôt de sable et de gravier (1) stratifié (plage) coiffant de l'argile grise (2), caillouteuse et fossilifère (3.7.67).

\section{LA FALAISE MICMAC}

\section{Étendue}

La falaise Micmac se rencontre un peu partout sur les deux rives du Saint-Laurent estuarien (fig. 1) mais aussi dans le golfe et au Labrador (Daly, 1920). Sur la rive sud, elle est quasi continue entre Lévis et Sainte-Anne-des-Monts. Sur la rive nord, elle domine le paysage littoral entre Montmorency et CapTourmente. On en trouve des lambeaux dans Charlevoix, en particulier à Petite-Rivière, Baie-Saint-Paul, La Malbaie ainsi qu'à la pointe aux Alouettes. II en existe aussi de beaux tronçons sur la haute Côte Nord, notamment à GrandesBergeronnes, aux Escoumins, entre Longue-Rive et Portneufsur-Mer, et à Ragueneau. On la retrace aussi à plusieurs endroits sur la moyenne et la basse Côte Nord jusqu'à BlancSablon (Dubois, 1980). La falaise Micmac peut aussi être observée sur la plupart des îles du Saint-Laurent : d'Orléans, Madame, aux Raux, aux Grues, aux Coudres et aux Lièvres dans le moyen estuaire; Verte, aux Basques, Saint-Barnabé et d'Anticosti dans l'estuaire maritime et le golfe. Elle existe également dans le haut estuaire du Saint-Laurent, notamment entre Grondines et Cap-Rouge sur la rive nord, et entre Lotbinière et Saint-Nicolas sur la rive sud. Sa longueur va de quelques kilomètres à quelques dizaines de kilomètres sans interruption. C'est le cas entre l'anse au Lard (Pointe-au-Père) et la pointe aux Cenelles (baie de Mitis) (fig. 2b), sur une longueur de $25 \mathrm{~km}$, et entre Les Boules et Rivière-Blanche sur $31 \mathrm{~km}$.
A. An oblique air photograph of the Micmac shoreline on the north side of ille d'Orléans showing a portion of the tidal zone, the low terrace (Mitis), the Micmac cliff and terrace, and a fourth terrace; all surfaces and escarpments are cut into bedrock (Cambro-ordovician slates) (89. 6. 5).

B. An oblique air view, in winter, of the Micmac shoreline between Sainte-Luce-sur-Mer and Sainte-Flavie which is typical of the area between Rimouski and Sainte-Anne-des-Monts. Cut into clay and bedrock, the Micmac cliff is a major coastal landform. Relatively narrow, the Mitis terrace is composed of sand and gravel (beaches) overlying a relict rock platform that outcrops in the intertidal zone (91. 3. 21).

C. Micmac cliff and Mitis terrace at Neuville, upper St. Lawrence estuary. Entirely cut into bedrock (shale), the former cliff is approximately $15 \mathrm{~m}$ high. The Mitis terrace is composed of small fragments of shale, one to two metres thick, overlying a rock platform which outcrops in the intertidal zone (89. 4. 8).

D. Micmac cliff and Mitis terrace on the south shore of ile aux Coudres. The rock cliff is locally covered by a thin sandy gravel deposit (beaches). The narrow Mitis terrace is composed of sand and gravel (beaches), overlying a rock platform which is exposed in the upper intertidal zone (86. 8. 20).

E. In the area of Rivière Tartigou (between Baie-des-Sables and Rivière-Blanche), the Micmac cliff is cut into a stony clay deposit (diamicton) and bedrock (shale-slates). At this locality, the Mitis terrace is composed of one to two metres of sand and gravel (beaches) overlying a relict rock platform (92. 7. 22).

F. A vertical section in the Micmac cliff at Pointe-au-Père showing a stratified sand and gravel (1) deposit (beaches) overlying a fossiliferous stony marine clay (2) (67. 7. 3).

\section{Orientation et nature}

On constate trois orientations principales (tabl. II) de la falaise Micmac, en particulier sur la rive sud : Sud-ouest (13 sites) ou nord-est (18 sites), sur de courts secteurs, c'est-à-dire dans les rentrants délimités par des crêtes rocheuses. Les sites les plus typiques, orientés vers le $\mathrm{SO}$, se trouvent dans la région d'Andréville (Kamouraska), Rivière-du-Loup (Saint-Patrice et anse au Persil), pointe à la Loupe (L'Isle-Verte est), TroisPistoles (Tobin et cap Marteau), et Sainte-Félicitée ouest. À

\section{TABLEAU ॥}

Orientation de la falaise Micmac sur la rive sud de l'estuaire

\begin{tabular}{cc}
\hline Direction & Nombre de sites \\
\hline SO & 13 \\
OSO & 2 \\
O & 6 \\
NO & 23 \\
ONO & 2 \\
NNO & 2 \\
NE & 18 \\
NNE & 4 \\
N & 4 \\
\hline
\end{tabular}




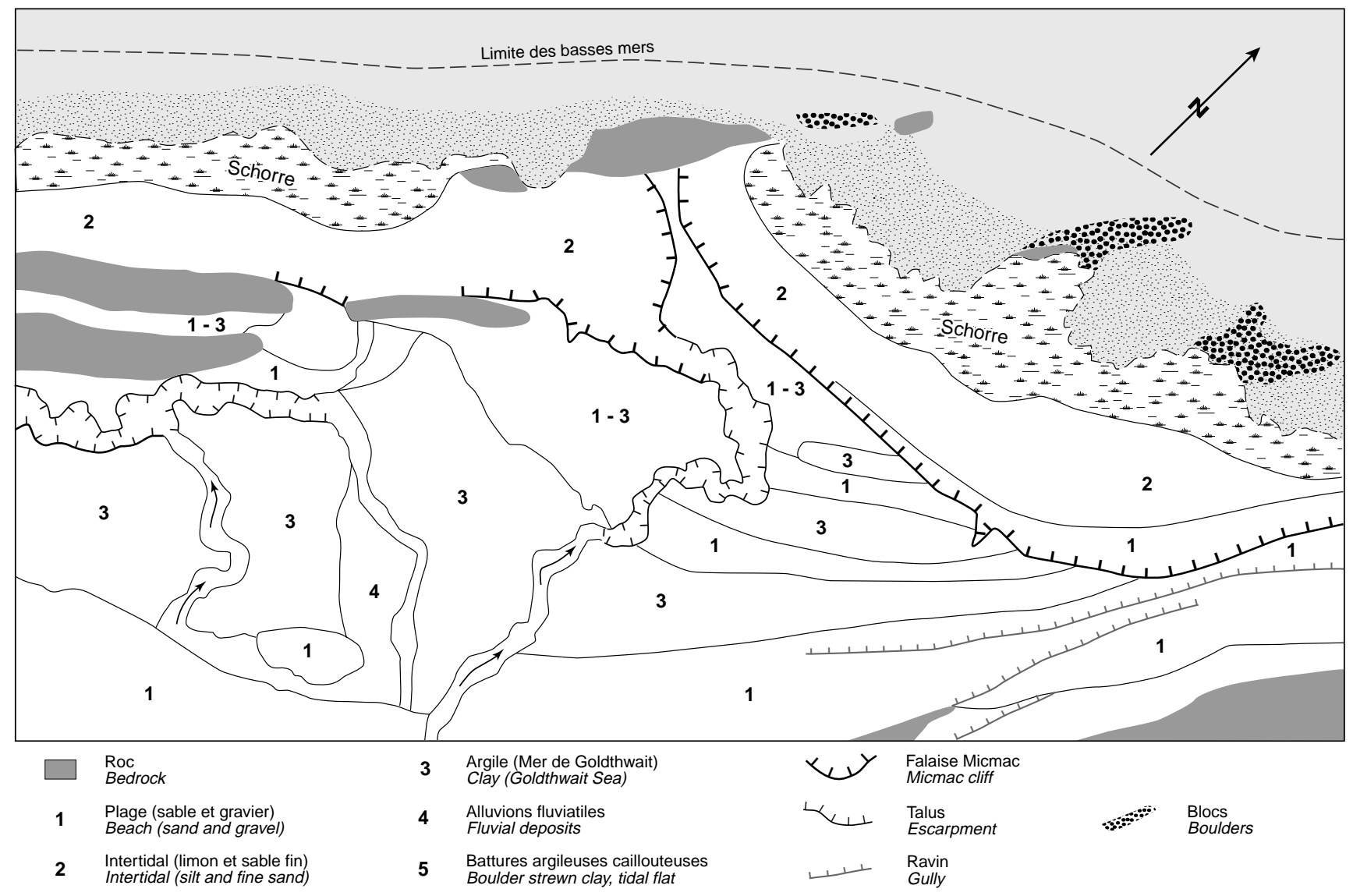

FIGURE 3. Schéma géomorphologique du secteur littoral à Rivièredes-Caps, entre Andréville et Le Portage, montrant la position et le tracé de la falaise Micmac, taillée principalement dans l'argile. Plusieurs complexes de plages de sable et gravier recouvrent l'argile de la Mer de Goldthwait. La terrasse Mitis est relativement étroite (secteur au sud de la route) et fusionne avec l'ancien schorre; elle est formée de sable et gravier reposant sur une surface argileuse. Une large batture argileuse avec des cailloux prolonge le marais intertidal vers le large.

ces endroits, la falaise Micmac est taillée dans l'argile de la Mer de Goldthwait. Les principaux sites orientés vers le NE sont localisés à Saint-Vallier (anse de Bellechasse), Kamouraska, Rivière-des-Caps (fig. 3), Trois-Pistoles, SaintFabien-sur-Mer, Sainte-Luce-sur-Mer et la rive ouest de la baie de Mitis. À ces endroits, la falaise est taillée dans l'argile. Au Cap-à-l'Orignal, au cap Enragé et à Bic (Rivière-Hattée), la falaise est plutôt taillée dans des rudites (plages). Les directions SO et NE correspondent aux vents dominants et aux plus longs fetches observables dans l'estuaire du Saint-Laurent. Ils sont donc les plus exposés et susceptibles d'être érodés par les agents littoraux.

Dans la majorité des secteurs des rives sud et nord, la falaise Micmac est plutôt parallèle au littoral actuel. Elle est tantôt entièrement rocheuse (fig. 2c-2d), tantôt partiellement rocheuse, c'est-à-dire formée d'une petite crête, rocheuse à la base, qui est recouverte d'argile ou d'un diamicton glaciomarin (fig. 2e); ces dépôts sont parfois coiffés de un à deux mètres de rudites (plages) (fig. 2f). Certains secteurs
A schematic geomorphic map of the Rivière-des-Caps area, between Andréville and Le Portage, showing the emplacement of the Micmac cliff mainly cut into Goldthwait Sea clay, which is covered by several raised beaches. Relatively narrow, the Mitis terrace is made of a thin beach deposit overlying a clay substrate. The upper intertidal zone is occupied by a tidal marsh, whereas the lower zone is a clay surface locally boulder-strewn.

(23 sites) sont entièrement en argile (L'Isle-Verte, Sainte-Lucesur-Mer, Sainte-Flavie et Matane).

On trouve en outre la falaise Micmac en argile au fond de quelques petits rentrants de forme arrondie (Les Méchins, PetitsCapucins, Cacouna) avec exposition vers le N, NNE et NNO.

\section{Position sur le rivage}

La distance entre le pied de la falaise Micmac et le rivage actuel (niveau des hautes mers) varie d'un secteur à l'autre. À quelques endroits (anse de Bellechasse, cap Enragé, baie de Mitis, Matane), la falaise est en contact avec la mer et érodée lors des hauts niveaux (fig. 4a). À maints endroits, elle se trouve à une distance allant de 30 à $120 \mathrm{~m}$ (secteur entre Les Boules et la rivière Tartigou), de 100 à $200 \mathrm{~m}$ (entre la rivière Tartigou et Rivière-Blanche), de 100 à 475 m (entre SainteLuce-sur-Mer et Sainte-Flavie); à plusieurs endroits, elle est relativement éloignée : 200 à 800 m (Berthier-sur-Mer, côte de Beaupré, Neuville) alors que dans les secteurs où il y a des 
îles côtières, (Kamouraska, L'Isle-Verte, Trois-Pistoles) certains segments de la falaise Micmac argileuse se trouvent à plus d'un kilomètre de la limite du rivage actuel.

Tracé

Le tracé de la falaise Micmac est souvent rectiligne, en particulier lorsqu'elle correspond à une crête rocheuse parallèle au littoral; dans les rentrants, le tracé est plutôt courbe, arqué ou concave; à quelques endroits, il est plus ou moins sinueux (rive nord de l'île d'Orléans, entre Sainte-Luce-surMer et Sainte-Flavie, secteur de Petit-Matane). Dans les rentrants, la falaise argileuse est habituellement insérée entre deux crêtes rocheuses et a une forme arquée (Rivière-desCaps, pointe à la Loupe, Tobin).

\section{Hauteur de l'escarpement}

La hauteur de la falaise Micmac varie en fonction de sa nature. Elle est généralement plus haute lorsqu'elle est taillée dans le roc. En dehors de courts secteurs où l'escarpement mesure entre 5 et $10 \mathrm{~m}$, la hauteur de la falaise est comprise entre 10 et $20 \mathrm{~m}$, davantage même à certains endroits comme sur la côte de Beaupré, le versant nord de l'île d'Orléans, le secteur entre Donnacona et Cap-Rouge et sur la rive sud en face, ou encore sur la rive nord de l'île aux Lièvres où elle atteint 40-45 m (Dionne, 1992b). Lorsque la falaise est taillée dans le matériel meuble, sa hauteur est plus constante et comprise entre 5 et $15 \mathrm{~m}$ (fig. 4b). La base de la falaise est en général entre 4,5 et $6 \mathrm{~m}$ d'altitude.

\section{LA BASSE TERRASSE (MITIS)}

\section{Étendue}

L'étendue de la basse terrasse est à peu près la même que celle de la falaise Micmac dans l'ensemble de l'estuaire, excepté aux endroits où la falaise vient en contact avec le rivage actuel. Dans ce cas, elle semble avoir été érodée. La basse terrasse est aussi présente à quelques endroits dans le golfe du Saint-Laurent (Côte Nord et île d'Anticosti), à BlancSablon et sur la côte adjacente du Labrador, de même que sur la côte ouest de Terre-Neuve (Grant, 1992).

\section{Altitude}

L'altitude de la terrasse Mitis est assez constante; elle est comprise habituellement entre 5 et $8 \mathrm{~m}$, et plus souvent autour de $6 \mathrm{~m}$ d'où l'appellation «twenty-foot terrace » de Goldthwait (1911a). À Petite-Rivière, les deux segments de la basse terrasse n'ont pas la même altitude (6 et $8 \mathrm{~m}$ ) ni le même âge (Dionne, 1996b). La surface de la basse terrasse est rarement rigoureusement horizontale; il y a une faible pente vers le rivage; de plus les colluvions, fréquentes au pied de la falaise Micmac, augmentent souvent l'altitude de la basse terrasse dans sa partie arrière. Dans les secteurs où elle est particulièrement large (L'Isle-Verte, Kamouraska, Saint-Denis, Rivière-Ouelle et La Pocatière), la basse terrasse s'abaisse régulièrement jusqu'à 3,5 ou $4 \mathrm{~m}$ et se confond avec l'ancien schorre supérieur, forcément plus jeune. À ces endroits, la délimitation entre les deux unités est difficile, et souvent impossible à tracer en l'absence d'excavation de tranchées et de travaux de nivellement.

\section{Largeur}

La largeur de la terrasse Mitis est très variable et généralement équivalente à la distance de la falaise morte du rivage actuel. Par endroits, elle fait moins de $50 \mathrm{~m}$; à d'autres, elle mesure entre 100 et $200 \mathrm{~m}$, parfois entre 200 et $400 \mathrm{~m}$, alors qu'à quelques endroits sur la rive sud du moyen estuaire, elle excède $500 \mathrm{~m}$ et atteint même 1000 à $1200 \mathrm{~m}$ là où elle se confond avec la surface de l'ancien schorre supérieur.

À titre d'exemples, dans le secteur entre Pointe-au-Père et Sainte-Flavie (fig. 4c) où elle est constituée de plages sablograveleuses sur un substrat rocheux, la largeur moyenne est de 200 à $225 \mathrm{~m}$, avec un minimum de 70 et un maximum de $800 \mathrm{~m}$. À la pointe aux Cenelles (baie de Mitis), elle mesure 100 à $110 \mathrm{~m}$ de largeur; dans le secteur des Boules, elle fait entre 20 et 60 m seulement, alors qu'elle s'élargit vers Baie-des Sables, mesurant entre 80 et 150 m, et de 100 à 200 m entre cette localité et Rivière-Blanche. À Sacré-Cœur, à l'ouest de Rimouski, elle mesure entre 50 et 250 m, à Bic, 150 à 160 m, à Saint-Fabien-sur-Mer, 30 à $110 \mathrm{~m}$ et au Portage, 30 à $60 \mathrm{~m}$.

Dans le secteur amont du moyen estuaire, sur la rive sud de l'île aux Coudres (fig. 2d), la terrasse Mitis mesure entre 30 et $110 \mathrm{~m}$ de largeur, excepté dans le secteur SO (entre SaintLouis et Cap-à-la-Branche) où elle fait entre 600 et $700 \mathrm{~m}$. Elle est aussi très étroite sur la rive sud de l'île d'Orléans, où elle est formée de minces placages de rudites littorales reposant sur une plate-forme rocheuse, alors qu'elle est relativement large sur la rive nord, où des alluvions fines de type intertidal recouvrent aussi une plate-forme rocheuse. Entre le pont de l'île et Sainte-Famille, la basse terrasse mesure de 150 à 400 m, de Sainte-Famille à l'anse aux Canards, de 100 à $300 \mathrm{~m}$, mais elle atteint $600 \mathrm{~m}$ dans la petite anse aux Canards.

Sur la côte de Beaupré, entre Boischatel et ChâteauRicher, la terrasse Mitis mesure entre 200 et $700 \mathrm{~m}$ avec une moyenne de 300 à $350 \mathrm{~m}$, mais elle se rétrécit entre 150 à $200 \mathrm{~m}$, à Sainte-Anne-de-Beaupré ; par contre, elle est très large à Saint-Joachim atteignant $800 \mathrm{~m}$. Bien développée sur les deux rives de l'île aux Grues, elle mesure entre 50 et $225 \mathrm{~m}$ du côté nord et 30 à $200 \mathrm{~m}$ du côté sud.

Sur la rive sud du moyen estuaire, aux endroits où la basse terrasse correspond à un substrat argileux voilé de sédiments fins intertidaux, la largeur est beaucoup plus grande que dans les secteurs rocheux. À titre d'exemples, mentionnons qu'à Andréville et Saint-Germain-de-Kamouraska, elle mesure entre 400 et $450 \mathrm{~m}$; dans le secteur central et oriental de la baie de Kamouraska, entre 1000 et 1500 m (fig. 5); de La Pocatière à Rivière-Ouelle, entre 700 et 1400 m; dans le secteur des Aulnaies-Village, entre 350 et $600 \mathrm{~m}$; entre les rivières Tortue et Trois-Saumons, 500 à $600 \mathrm{~m}$, alors qu'à Berthier-sur-Mer, la largeur est de l'ordre de $800 \mathrm{~m}$.

La situation ne diffère guère dans le haut estuaire ; la largeur de la terrasse Mitis est de 550 à $600 \mathrm{~m}$ à Saint-Augustin 

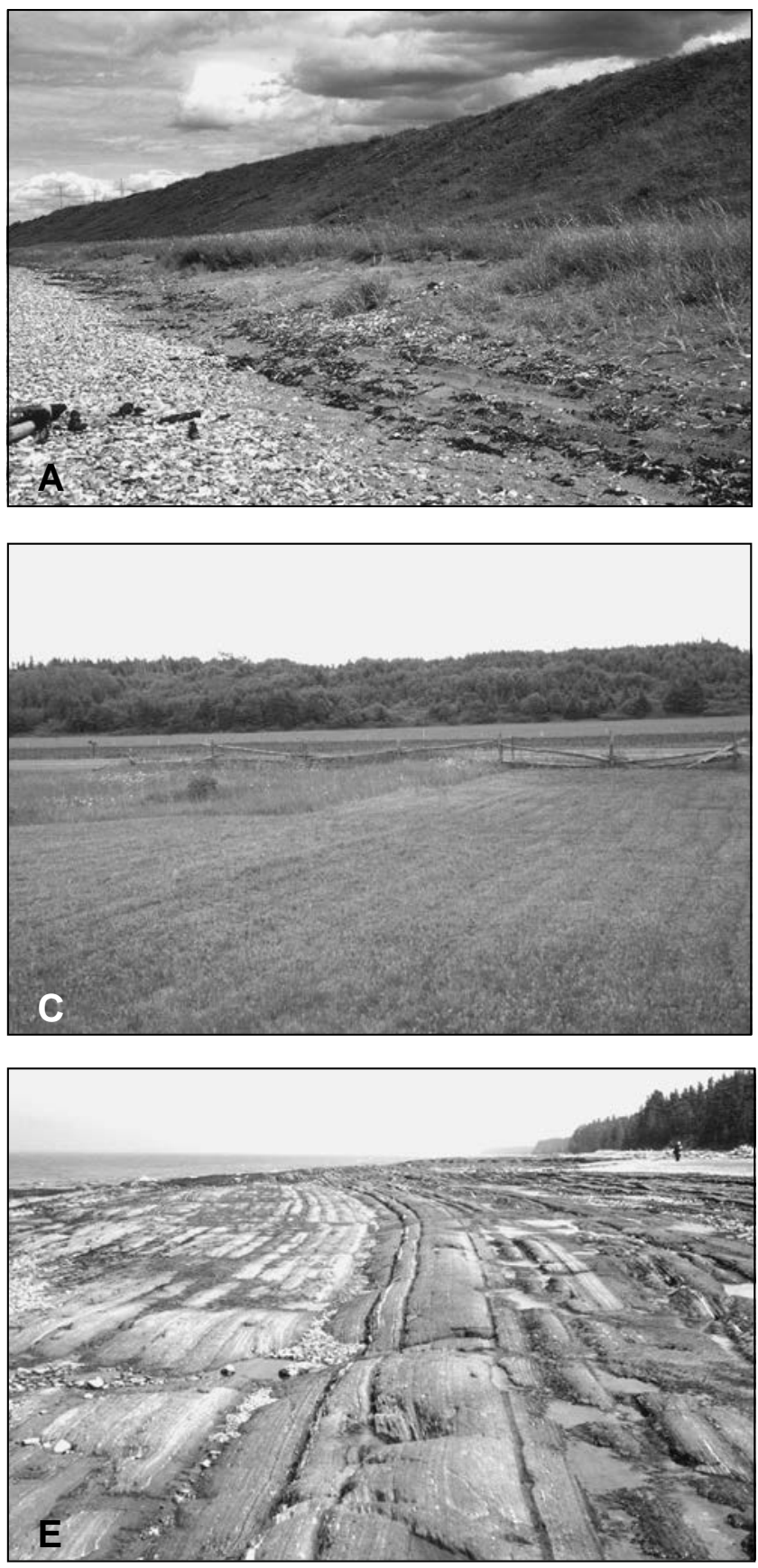

dans le secteur de la côte à Racette et de 200 à $700 \mathrm{~m}$ dans le secteur des îlets Dombourg, mais elle est de seulement 100 à $200 \mathrm{~m}$ à l'ouest de Neuville. En amont, il existe plusieurs secteurs où elle est relativement large. C'est le cas à l'est de Portneuf sur une distance d'environ $5 \mathrm{~km}$, où elle fait entre 300 et $600 \mathrm{~m}$, et à Deschambault, où sa largeur atteint entre 400 et 800 m, alors qu'à Grondines, elle mesure entre 600 et $1300 \mathrm{~m}$. Par contre, sur la rive sud, les lambeaux de la terrasse Mitis sont plutôt étroits, à l'exception des secteurs de Lotbinière où ils font entre 300 et $400 \mathrm{~m}$, de la pointe à Platon, où ils sont de 200 à $425 \mathrm{~m}$ de largeur, et Les Fonds, à l'ouest de Saint-Antoine-de-Tilly, où ils mesurent de 50 à
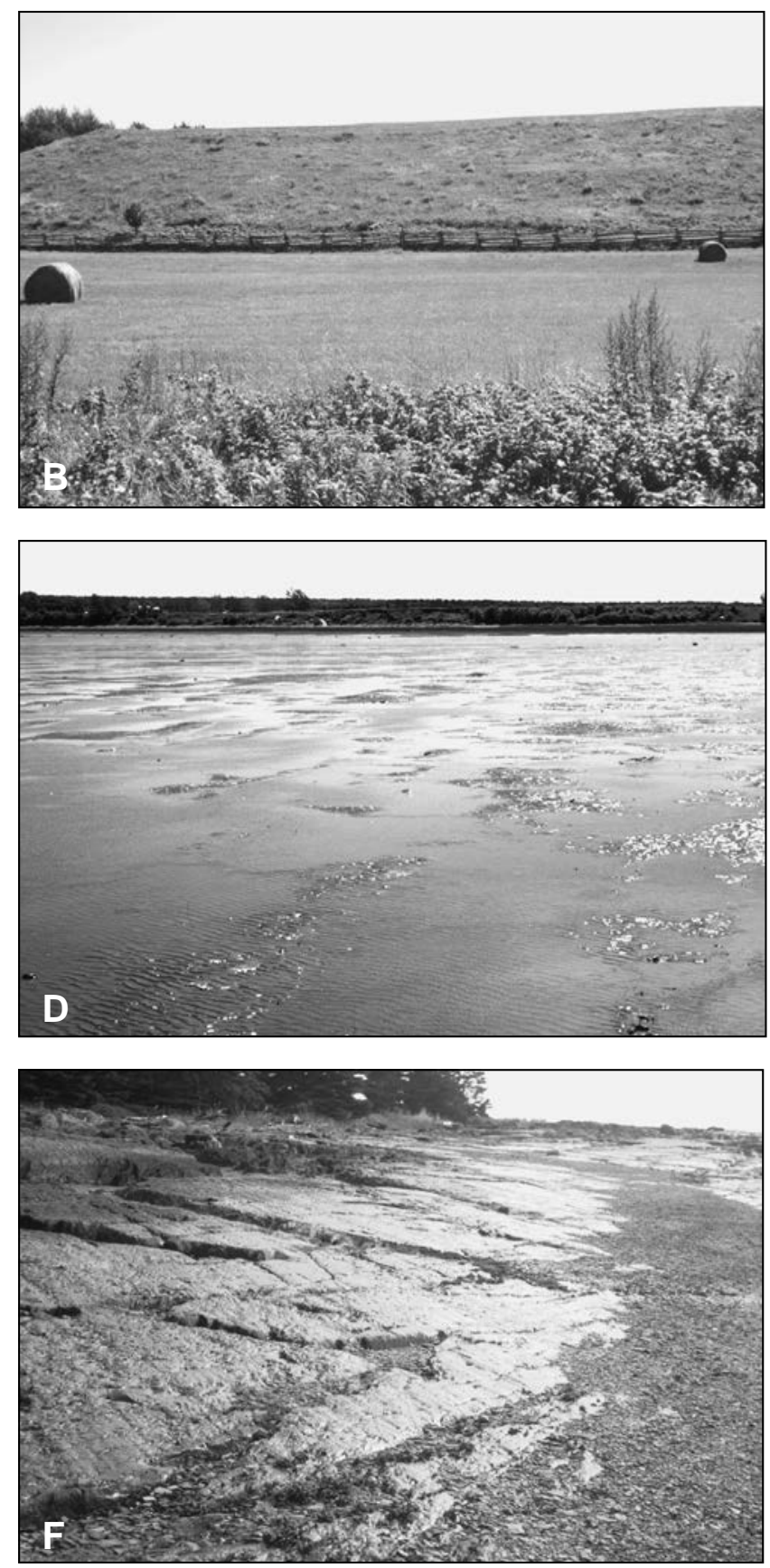

$150 \mathrm{~m}$. Bref, quelle que soit sa nature, la largeur de la terrasse Mitis est loin d'être constante.

\section{Nature}

La basse terrasse est constituée de divers matériaux: 1) sur de longs secteurs, en particulier sur la rive sud de l'estuaire maritime, elle est constituée de sable et gravier (plages), de un à trois mètres d'épaisseur, reposant sur un substrat rocheux, en général des schistes, correspondant à la plate-forme relique qui vient aboutir à la falaise morte (Micmac). Ce dépôt littoral de rudites est souvent fossilière, 
$\leftarrow$ FIGURE 4A. Falaise Micmac à Matane dans le secteur entre la rivière et Petit-Matane. Taillée dans un dépôt d'argile marine caillouteuse, la falaise est encore active. Si elle a déjà existé à cet endroit, la terrasse Mitis a été érodée; à remarquer l'étroit cordon littoral de tempête au pied de la falaise (22. 7.92)

B. Vue typique de la falaise Micmac et de la terrasse Mitis dans le secteur entre Sainte-Luce-sur-Mer et Sainte-Flavie. Taillée dans de l'argile marine caillouteuse et le roc (schistes), la falaise mesure une dizaine de mètres de hauteur ; à son pied, la terrasse Mitis, qui est parfois relativement large (600 à $800 \mathrm{~m}$ ), est composée de un à trois mètres de sable et de gravier (plages) reposant sur une ancienne plate-forme rocheuse (24.6.96).

C. La falaise Micmac et la terrasse Mitis à Saint-Patrice (Rivière-duLoup Ouest). La falaise est entièrement taillée dans de l'argile marine caillouteuse, alors que la terrasse Mitis est constituée d'un mince dépôt intertidal limoneux reposant sur une surface d'érosion taillée dans l'argile. À cet endroit, la falaise morte est à plus de $500 \mathrm{~m}$ du rivage actuel (28. 8. 96).

D. Large batture argileuse dans la région de l'anse de Bellechasse, dans le moyen estuaire du Saint-Laurent. Taillée dans l'argile de la Mer de Goldthwait, la surface argileuse s'étend jusqu'au pied d'une falaise meuble de $8 \mathrm{~m}$ de hauteur et elle est partiellement recouverte d'une mince couche de vase fraîche (24.6. 83).

E. Plate-forme rocheuse intertidale sur la rive nord de l'île SaintBarnabé (Rimouski) ; cette plate-forme d'érosion relique est typique de la rive sud du Saint-Laurent, en particulier entre Rimouski et SainteAnne-des-Monts (23. 7. 01).

F. Plate-forme rocheuse taillée dans les schistes à la pointe Santerre (Bic); la surface polie et striée indique un écoulement des glaces vers le NNE $\left(10^{\circ}-20^{\circ}\right)$ et fournit une preuve de l'existence préalable de la plate-forme (23.7.94).

en particulier dans le secteur entre Baie-des-Sables et PetitMatane. 2) La basse terrasse est aussi, à l'occasion, constituée d'argile, notamment à Rivière-du-Loup, L'Isle-Verte, Cacouna et Trois-Pistoles. II s'agit dans ce cas d'une surface d'érosion aboutissant à la falaise morte, elle aussi argileuse, et qui se poursuit dans la zone intertidale actuelle. 3) À plusieurs endroits, la basse terrasse est formée d'un dépôt intertidal (sable fin et limon ou vase stratifiés), contenant parfois des fossiles, mais surtout des débris organiques ou du bois, notamment à Berthier-sur-Mer, Kamouraska et La Pocatière. Ce dépôt repose généralement sur un substrat argileux bien que par endroits comme sur la côte de Beaupré et la rive nord de l'île d'Orléans, il voile la plate-forme rocheuse. 4) La terrasse Mitis peut aussi être constituée de plusieurs unités lithologiques superposées : plages de sable et gravier en surface recouvrant des sédiments intertidaux qui eux-mêmes reposent tantôt sur un diamicton ou du till, ou encore sur du roc (plate-forme rocheuse relique, comme à Petite-Rivière, à la pointe aux Alouettes, à Saint-Augustin et à Deschambault (Dionne, 1996a, 1996b). La nature de la terrasse Mitis est donc loin d'être uniforme partout où elle existe. II faut en tenir compte dans l'interprétation.

\section{LA ZONE INTERTIDALE ACTUELLE}

\section{Largeur}

La largeur de la zone intertidale varie généralement d'une centaine à quelques centaines de mètres mais, à certains endroits, elle atteint un kilomètre ou davantage. La batture de Mille-Vaches, sur la rive nord, entre Les Escoumins et Portneuf-sur-Mer, mesure entre un et deux kilomètres; celle
A. Micmac cliff at Matane in the area between the river and PetitMatane. Cut into a stony marine clay, the cliff is still active. The absence of the Mitis terrace at the foot of the cliff is probably related to a former period of erosion; note the narrow storm beach ridge at the foot of cliff (92. 7. 22).

B. A typical view of the Micmac cliff and Mitis terrace in the area between Sainte-Luce-sur-Mer and Sainte-Flavie. Cut into stony marine clay overlying a rock ridge, the escarpment is approximately $10 \mathrm{~m}$ high. At the foot of cliff, the Mitis terrace, which is locally up to $800 \mathrm{~m}$ wide, is made of sand and gravel (beaches) overling a relict rock platform (96. 6. 24).

C. The Micmac cliff and Mitis terrace at Saint-Patrice (Rivière-duLoup). The cliff is entirely cut into a stony marine clay deposit, whereas the Mitis terrace is composed of a thin intertidal silty deposit overlying an erosion surface cut into clay. At this locality, the former cliff is located over $500 \mathrm{~m}$ from the present shoreline (96. 8. 28).

D. A wide clay tidal flat in the area of Anse de Bellechasse, middle St. Lawrence estuary. Cut into Goldthwait Sea clay, the erosion surface extends landward to a $8 \mathrm{~m}$ high cliff and is locally covered by a thin fresh mud deposit (83. 6. 24).

E. Rock platform in the intertidal zone on the north shore of Ille SaintBarnabé (Rimouski). This relict erosion feature is typical of the area between Rimouski and Sainte-Anne-de-Monts (01.7.23).

F. Rock platform cut into slates at Pointe Santerre (Bic); the polished and striated surface shows a glacier ice flow to the NNE $\left(10^{\circ}-20^{\circ}\right)$, and provide evidence for the existence of the platform before the last glacial event (94. 7. 23).

en face de L'Isle-Verte et de Trois-Pistoles, entre deux et trois kilomètres; celle en face de Kamouraska, entre trois et quatre kilomètres alors que la batture aux Alouettes, à l'embouchure du Saguenay, excède cinq kilomètres. Ces très larges battures sont toutes taillées en roches meubles argileuses. Les battures rocheuses sont plus étroites, excédant rarement $300 \mathrm{~m}$ de largeur, excepté sur les rives du haut estuaire du Saint-Laurent (Dionne et Brodeur, 1988a).

\section{Aspect général et nature}

En général, la zone intertidale meuble correspond à une surface plane et faiblement inclinée vers la limite des basses mers (pente inférieure à $1^{\circ}$ ) qui est, ici et là, caractérisée par des micro-formes (Dionne, 1985a, 1988c).

La nature de l'estran (batture) varie en regard de la nature même de la falaise Micmac. Là où la falaise est argileuse (fig. 4d), la batture l'est aussi et elle est souvent couverte de blocs isolés ou de petits cailloux formant des dallages (Dionne, 1987 ; Dionne et Poitras, 1996, 1998) ; là où la falaise est rocheuse, on trouve une plate-forme intertidale taillée dans le même substrat, la plupart du temps des schistes, occasionnellement du grès, ou les deux en association, cas fréquent sur la rive sud. En amont de Québec, les platesformes rocheuses mesurent fréquemment entre 500 et $800 \mathrm{~m}$ de largeur et sont quasi horizontales (Dionne et Brodeur, 1988a, 1988b). Les plates-formes sur la rive sud du SaintLaurent estuarien et sur les îles (fig. 4e) présentent une morphologie de détail variée et sont rarement aussi planes et horizontales que celles du haut estuaire (Brodeur et Allard, 1983). Dans d'autres secteurs, l'estran est composite, 


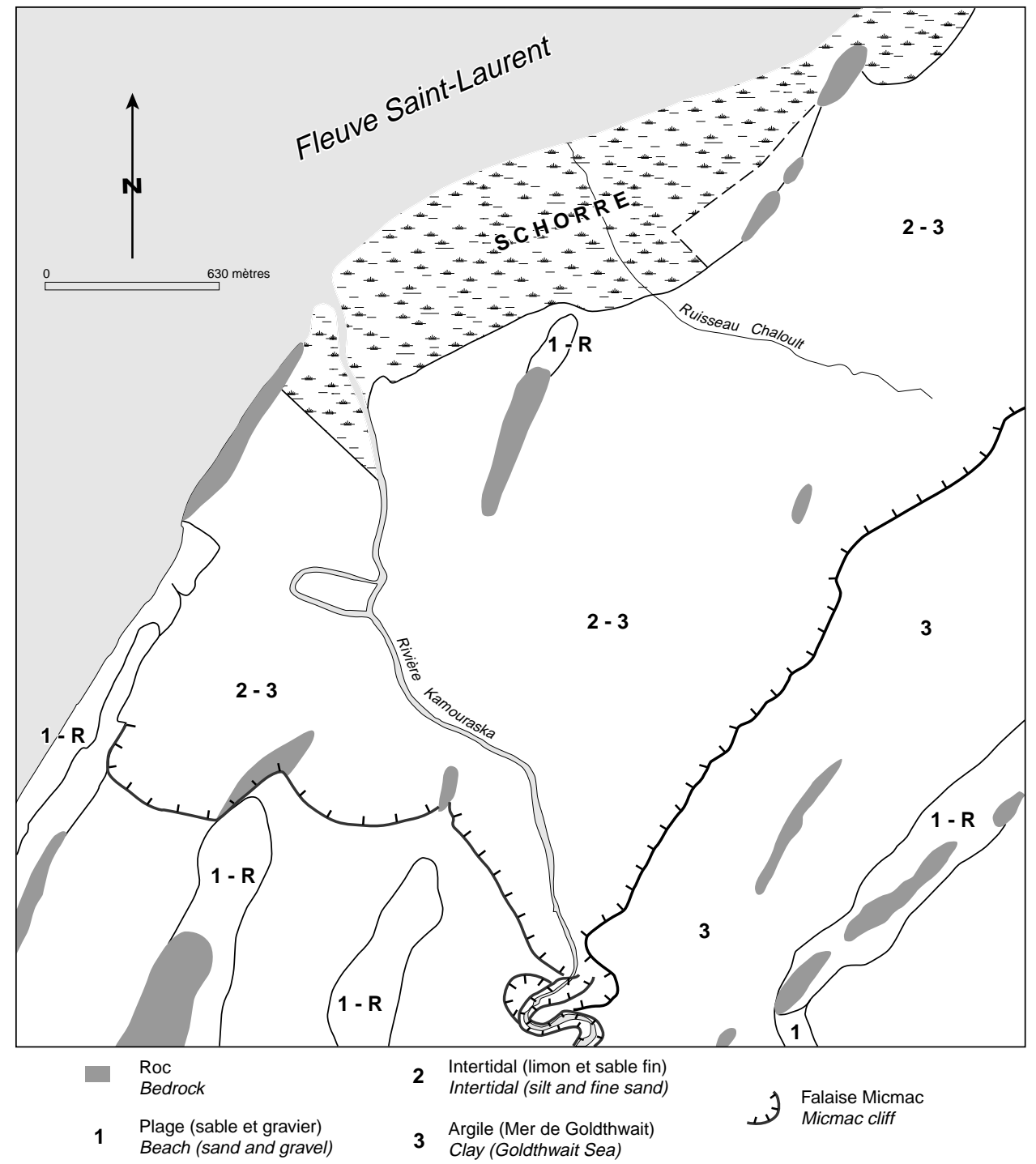

FIGURE 5. Schéma géomorphologique de la région de Kamouraska montrant l'emplacement de la falaise Micmac taillée dans l'argile de la Mer de Goldthwait, ainsi que la terrasse Mitis composée d'un dépôt intertidal limoneux recouvrant une large surface d'érosion dans l'argile. La partie supérieure du rivage comprend un schorre supérieur partiellement poldérisé.

A schematic geomorphic map of the area of Kamouraska showing the Micmac cliff cut into Goldthwait Sea clay, and the wide Mitis terrace made of a silty intertidal deposit overlying an erosion surface cut into clay. The upper part of the intertidal zone is occupied by a high marsh partially dyked.

c'est-à-dire qu'il est formé à la fois par des lambeaux de plate-forme rocheuse et par des dépôts meubles; souvent, la plate-forme rocheuse occupe la partie supérieure de l'estran et l'argile, la partie inférieure; par endroits, cependant, l'argile est concentrée dans des dépressions orientées SO-NE entre des lambeaux de plate-forme, le tout formant une surface plane appelée batture. À quelques endroits, la surface du bas estran est vaseuse (Montmagny, île aux Grues, CapTourmente), alors qu'à d'autres endroits, elle est sableuse (Saint-Fabien-sur-Mer, anse aux Coques à Sainte-Luce-surMer, baie du Ha! Ha! à Cap-à-l'Orignal). II s'agit souvent de placages peu épais (rarement plus d'un mètre) voilant l'argile ou un dépôt intertidal limoneux. À Petite-Rivière (Charlevoix), le bas estran, d'environ un kilomètre de largeur, est taillée dans divers dépôts meubles quaternaires (sable, argile, till ou diamicton et varves) et recouvert par endroits de sable ou de vase (Dionne, 1996b).

\section{CONCLUSION}

Ainsi, les trois principales composantes de la ligne de rivage Micmac sont loin d'être uniformes sur l'ensemble des rives du Saint-Laurent estuarien. Par endroits la falaise est rocheuse, à d'autres, meuble et souvent composite ou mixte (meuble et rocheuse); elle est plus ou moins éloignée du rivage actuel, rectiligne ou sinueuse, alors que sa hauteur varie d'un secteur à l'autre, bien que l'altitude de la base soit relativement uniforme dans les secteurs émergés. De leur côté, la basse terrasse et la zone intertidale présentent, elles aussi, diverses caractéristiques, notamment la largeur et la nature dont il faut tenir compte dans l'analyse du relief.

\section{PRINCIPAUX TYPES DE RIVAGE MICMAC}

Sur l'ensemble du littoral du Saint-Laurent, le rivage Micmac présente plusieurs types (fig. 6) appartenant à deux grandes catégories. Les deux plus fréquents sont les suivants.

1) Dans les secteurs rocheux de la rive sud et de la plupart des îles, la falaise morte est rocheuse avec, à son pied, une plate-forme d'érosion qui affleure dans la zone intertidale (fig. 6a). Ces deux unités forment ce que Locat (1977) a appelé «la surface de Micmac». Toutefois, la plate-forme rocheuse est recouverte de 1 à $3 \mathrm{~m}$ de sable et de gravier stratifié (plages). Cette accumulation, comme on le sait, constitue la 


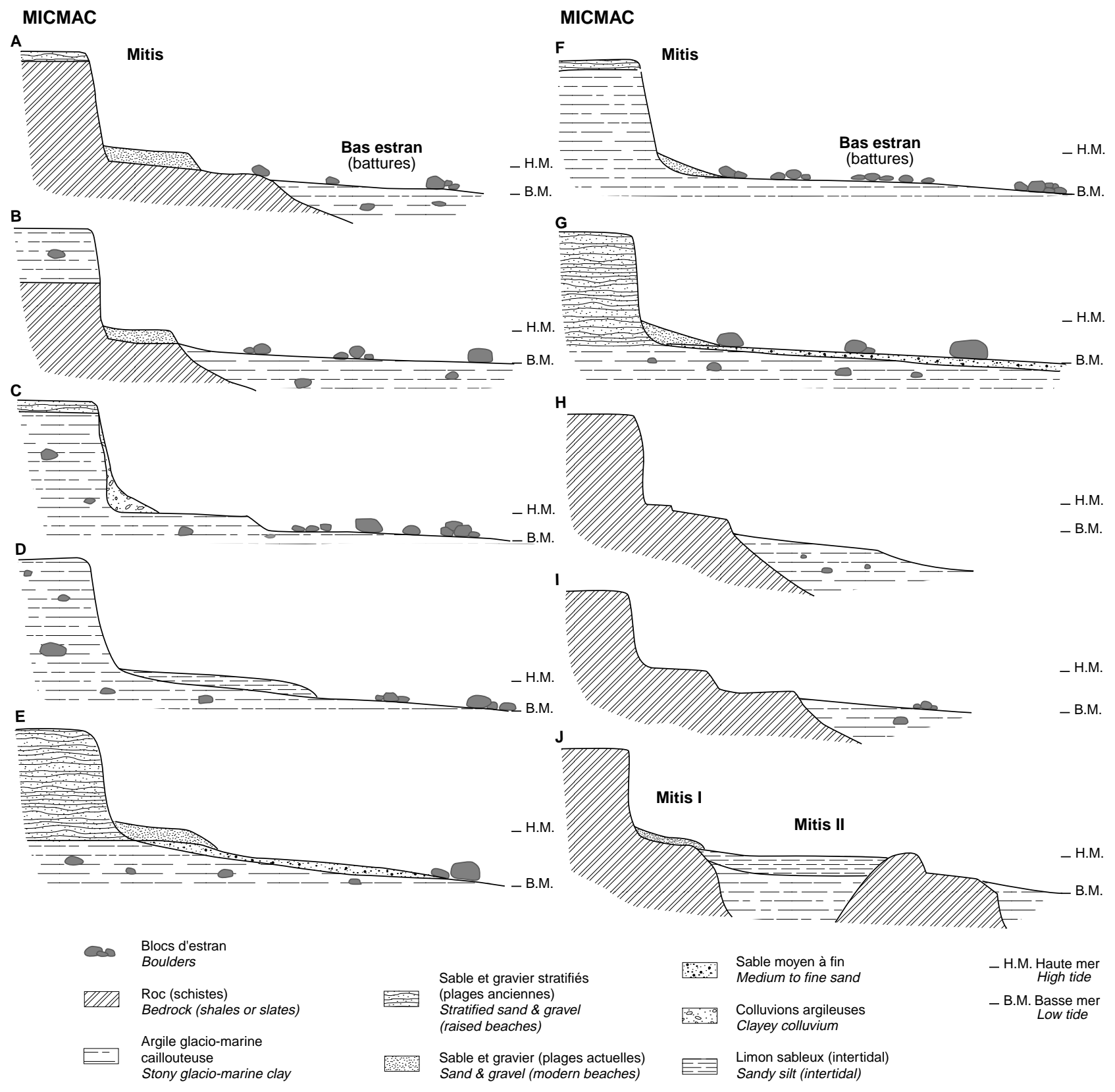

FIGURE 6. Coupes schématiques des principaux types de la ligne de rivage Micmac, illustrant les trois composantes.

terrasse Mitis de Dionne (1963), jadis appelée Micmac par Goldthwait (1911a). La plate-forme rocheuse d'érosion, nue et émergée, a rarement été observée en milieu naturel, sinon à Berthier-sur-Mer (près du quai), où on peut voir deux replats étroits et une petite falaise taillés dans des schistes gris et rouges (fig. 6i). Par endroits, la plate-forme rocheuse est recouverte d'alluvions fines (sable fin et limon), comme sur la Côte-de-Beaupré et la rive nord de l'île d'Orléans.

2) Le second type est entièrement en roches meubles (fig. $6 \mathrm{~b}$ à $6 \mathrm{~g}$ ). La falaise morte et la plate-forme ont été toutes deux taillées dans l'argile de la Mer de Goldthwait. Dans ce
Sketches of main types of the Micmac shoreline, showing the three components.

cas, la basse terrasse peut être constituée, à son pied, d'un mince placage (1 à $2 \mathrm{~m}$ ) de sable et gravier (plages) ou encore d'alluvions fines de type intertidal ou parfois de dépôts divers plus complexes, comme à Petite-Rivière (Dionne, 1996b), à la pointe aux Alouettes (Dionne, 1996a) et à la pointe de Mille-Vaches (Portneuf-sur-Mer).

II existe aussi plusieurs variantes à ces deux types fondamentaux. Dans l'une d'elles, la falaise morte est taillée à la fois dans la roche consolidée et dans les dépôts meubles (fig. 6b), généralement de l'argile, qui peut être ou non coiffée de sable et de gravier (plages). Quand elle existe, la plate-forme rocheuse 
occupe tantôt une étroite partie de la zone intertidale, tantôt la moitié, tantôt l'entièreté.

II en va de même pour le second type fondamental (fig. 6c, 6 e et 6f) ; la falaise morte peut être entièrement ou partiellement argileuse ou encore taillée dans un dépôt de till (PetiteRivière), de diamicton glacio-marin (Rivière-Blanche, PetitMatane) ou de sable et de gravier (cap Enragé) (Dionne, 2001c) et, parfois même, dans de l'argile coiffée de sédiments intertidaux (Montmagny, Saint-Vallier). Dans la plupart de ces cas, la batture est, elle aussi, taillée dans les mêmes matériaux mais le plus souvent dans l'argile. En général, la basse terrasse est très étroite et parfois même absente (fig. $6 \mathrm{f}$ et $6 \mathrm{~g}$ ) (baie de Mitis, Matane, cap Enragé, anse de Bellechasse).

Il existe cependant des cas complexes. À Berthier-sur-Mer, par exemple (fig. 6j), la falaise morte taillée dans des schistes gris et rouges mesure une vingtaine de mètres de hauteur. À son pied, on observe une étroite plate-forme rocheuse voilée de fragments de schistes locaux (ancienne plage) formant une basse terrasse qui se termine par un petit talus (moins d'un mètre), juste au nord de la route. Entre ce point et le rivage actuel, l'espace est occupé par une large terrasse (800 m) constituée d'alluvions fines (faciès intertidal), de un à deux mètres d'épaisseur, qui repose sur un substrat argileux (surface d'érosion relique). Cette basse terrasse est elle-même isolée du rivage actuel par une crête rocheuse arasée taillée en plate-forme moderne du côté externe (offshore).

Bref, il existe plusieurs types de rivage correspondant à la ligne de rivage Micmac qu'il importe de reconnaître et de distinguer avant de chercher une explication générale.

\section{ÂGE RELATIF DES DIVERSES COMPOSANTES DE LA LIGNE DE RIVAGE MICMAC}

Établir l'âge de la ligne de rivage Micmac nécessite que l'on distingue les trois composantes dont nous venons de parler. Si l'âge de la basse terrasse ne pose pas de problème, car on y trouve du matériel organique (bois, coquillages) qui peut être daté, ce n'est pas le cas de la falaise morte ou de la plateforme rocheuse, puisqu'elles ont été taillées dans les dépôts meubles quaternaires ou holocènes qui ne peuvent être datés qu'approximativement.

\section{LA FALAISE MICMAC ET LA PLATE-FORME ASSOCIÉE}

\section{La falaise et la plate-forme rocheuses}

La falaise rocheuse et la plate-forme associée sont des formes anciennes héritées qui ont été réoccupées par la mer, à l'Holocène, et qui ont été partiellement retouchées. II n'existe pas de discontinuité entre la falaise et la plate-forme; les deux appartiennent au même système géomorphologique.

À quelle époque précise et par quels agents cette surface rocheuse et la falaise ont-elles été taillées? On l'ignore. On peut affirmer, cependant, que la surface rocheuse au pied de l'escarpement relique existait avant le passage du dernier glacier. En effet, à maints endroits dans le Saint-Laurent estuarien, on trouve des marques glaciaires (fig. 4f) à la fois sur le schiste et le grès (Dionne, 1972, 2001a). À d'autres endroits, le profil glaciaire est fort bien conservé, ce qui témoigne de retouches relativement mineures par les agents littoraux postglaciaires. De plus, à quelques endroits, la surface rocheuse, et parfois la falaise elle-même, sont recouvertes de dépôts glaciaires ou autres (till, diamicton, argile caillouteuse glaciomarine, varves) (LaSalle, 1972, 1984, 1987; LaSalle et al., 1977; Dionne, 1972, 1996b; Occhietti, 1989). On peut donc en conclure que ces deux éléments du paysage sont pré-wisconsiniens, probablement sangamoniens, sinon plus anciens, et qu'ils ont été façonnés par les agents littoraux.

La plate-forme et la falaise rocheuses ont-elles été réellement façonnées lors du dernier interglaciaire (Sangamonien)? S'agit-il plutôt de formes littorales plus anciennes remontant au Tertiaire, qui auraient pu être simplement retouchées lors des divers interglaciaires du Quaternaire comme elles l'ont été au cours de l'Holocène et le sont encore de nos jours? II est impossible de répondre à cette question dans l'état actuel des connaissances. Plusieurs auteurs (Marshall et Thom, 1976; Harmon et al., 1981; Vacher et Hearty, 1989), cependant, estiment qu'au cours du Sangamonien, le niveau des mers était plus élevé de 4 à $6 \mathrm{~m}$ qu'actuellement, ce qui correspond à peu près au niveau de la plate-forme rocheuse fossilisée (substrat de la terrasse Mitis) observée aussi à TerreNeuve (Henderson, 1972) et en Nouvelle-Écosse (Grant, 1980, 1989 ; Stea, édit, 1987). Nous doutons cependant qu'il s'agisse de formes dues à un aplanissement subaérien de type fluviatile comme l'a préconisé Johnson (1925). Si ce type d'érosion permet d'expliquer certains aplanissements à l'intérieur des terres, il ne peut rendre compte de l'érosion de la plate-forme et de la falaise rocheuses constituant la «surface de Micmac ». D'ailleurs, la plate-forme rocheuse au pied de la falaise Micmac n'est pas la seule à être aplanie et à porter des marques glaciaires. À Sainte-Luce-sur-Mer par exemple, une excavation faite, il y a une trentaine d'années, à la surface de la terrasse Micmac, nous a permis d'observer une crête rocheuse (schistes) aplanie avec surface polie et striée recouverte de un à deux mètres d'argile caillouteuse. De même, la plupart des crêtes rocheuses appalachiennes de la zone côtière (Dionne, 1990, p. 46) et du rebord externe des hautes terres appalachiennes sont, elles aussi, taillées dans des schistes. Or, ces crêtes sont aplanies et leur surface est polie et striée. Si ces aplanissements sont forcément subaériens, étant situés au-dessus du niveau des mers postglaciaires connues, on ignore, cependant leur âge et les conditions paléoenvironnementales qui prévalaient alors. II s'agit probablement d'aplanissements pré-quaternaires (Bird, 1972). Dans le cas spécifique de la plate-forme Micmac, l'action des agents littoraux, y compris celle les glaces ne peut être ignorée (Goldthwait, 1933; Dionne et Brodeur, 1988b).

\section{La falaise et la batture en dépôt meubles}

Dans le cas où la falaise Micmac et la plate-forme (batture) sont toutes deux taillées dans l'argile ou un autre dépôt meuble, elles sont forcément postglaciaires. Si la période durant laquelle elles ont été érodées ne peut être déterminée avec certitude, nos données indiquent cependant qu'il y a eu deux phases d'érosion. La plus ancienne correspond à la 
Transgression laurentienne, c'est-à-dire à la remontée du niveau marin après la période de bas niveau comprise entre 6 et 7 ka environ (Dionne, 1988b). La deuxième phase est plus récente; elle correspond à une période de stabilité relative ou de légère transgression, vers 2,5-3 $\mathrm{ka}$, qui a précédé l'édification de la terrasse Mitis. En effet, à plusieurs endroits, nous avons obtenu des dates au radiocarbone de l'ordre de 3000 ans BP sur du bois et des coquillages au contact entre le substrat argileux érodé et le dépôt meuble composant la terrasse Mitis. En face du village de L'Isle-Verte, la plate-forme argileuse au pied de la falaise Micmac, a été datée de 4 ka (Dionne, 1999). À Montmagny, à Cap-Saint-Ignace et à l'anse de Bellechasse, (Dionne, 1977,1988a, 1988b, 2000), la falaise morte est taillée dans la terrasse de 8-10 m édifiée lors de la Transgression laurentienne. L'escarpement est forcément postérieur à l'abaissement du niveau ou du relèvement des terres qui, d'après les données disponibles, aurait débuté vers 4,5 ka dans ce secteur.

\section{LA TERRASSE MITIS}

Les données chronologiques (datations au ${ }^{14} \mathrm{C}$ ) concernent principalement la basse terrasse. À ce jour, nous disposons d'un grand nombre de dates pour les deux rives du moyen estuaire (tabl. III). Toutefois, plusieurs concernent des événements survenus après l'épisode Mitis proprement dit et ne peuvent servir à dater la basse terrasse.

Au total, 128 dates provenant de 36 localités ont été retenues. L'âge médian basé sur cet ensemble est de $1920 \pm 50 \mathrm{BP}$ (UL-327) avec un minimum de $1110 \pm 50 \mathrm{BP}$ (Beta-36102) et un maximum de $3170 \pm 70 \mathrm{BP}$ (UL-283). En retenant uniquement les médianes dans le cas des sites pour lesquels on dispose de trois dates ou plus, le total des dates au ${ }^{14} \mathrm{C}$ utilisées tombe à 43. Dans ce cas, la médiane est alors de $2030 \pm 80 \mathrm{BP}$ (Beta-10819), le minimum de $1360 \pm 70 \mathrm{BP}$ (Beta-38082) et le maximum de $3160 \pm 70 \mathrm{BP}$. On peut donc affirmer que l'âge médian de la terrasse Mitis est d'environ $2 \mathrm{ka}$.

Cette valeur générale demande cependant à être nuancée car à certains endroits, notamment à la pointe aux Alouettes, l'âge médian de la basse terrasse est inférieur d'environ 600 ans (Dionne, 1996a), alors qu'à d'autres endroits, notamment à Bic et à Cap-à-l'Orignal, il est plus ancien. Le tableau III fournit l'ensemble des dates retenues pour les diverses localités, alors que le tableau IV résume les données disponibles pour les trois régions de l'estuaire.

Pour la région de Québec et le haut estuaire, l'âge médian $(n-9)$ de la terrasse Mitis est de $2030 \pm 80 \mathrm{BP}$ (UL-1706) avec un minimum de $1970 \pm 80 \mathrm{BP}$ (UL-575) et un maximum de $2180 \pm 60$ BP (GSC-6304). Pour l'instant et compte tenu du petit nombre de dates disponibles et de sites pour lesquels elles sont connues, c'est le secteur où la terrasse Mitis est la mieux datée.

Sur la rive sud, la médiane pour l'ensemble des dates des 22 localités ( $n-40)$ est de $1980 \pm 50$ BP (UQ-601), mais l'écart entre le minimum de $1360 \pm 70 \mathrm{BP}$ (Beta-38 082) et le maximum de $3160 \pm 70$ BP (UL-283) est relativement grand. En retenant la médiane seulement pour les sites pour lesquels au moins trois dates sont disponibles, le total des dates tombe à
27. La médiane passe alors à $2240 \pm 140 \mathrm{BP}$ (QU-265). II convient aussi de mentionner que, dans ce secteur, l'âge médian $(n-19)$ calculé à partir des seules dates sur coquillages dans des sédiments littoraux (plages), entre le Portage et Grande-Vallée est de $2390 \pm 70$ BP (Beta-34763) avec un minimum de $1630 \pm 55 \mathrm{BP}$ (Dic-1276) et un maximum de $3170 \pm 60$ BP (Beta-13855). Pour le secteur en amont de TroisPistoles, les dates au radiocarbone obtenues en grande partie sur du bois ou de la matière végétale sont généralement plus jeunes, la médiane ( $n$-13) étant de $1800 \pm 60$ BP (UL-362).

Pour la côte nord, y compris Blanc-Sablon, l'âge médian (n-70) pour l'ensemble des dates est de $1910 \pm 70 \mathrm{BP}$ (UL-1938) avec un minimum de $1110 \pm 50$ BP (Beta-36102) à la pointe aux Alouettes et un maximum de $2800 \pm 200 \mathrm{BP}$ (UQ-1389) à Petite-Rivière. Toutefois, si on retient plutôt la médiane des dates aux sites qui en comptent au moins trois, notamment Petite-Rivière (24) et la pointe aux Alouettes (25), l'âge médian $(n-9)$ de la terrasse Mitis est plutôt de $2030 \pm 80$ BP (Beta-10819), avec un minimum de $1370 \pm 50$ BP (Beta-28370) et un maximum de $2760 \pm 60 \mathrm{BP}$ (UL-1679).

Comme nous l'avons déjà mentionné ailleurs (Dionne, 1996a), l'âge du segment résiduel de la terrasse Mitis à la pointe aux Alouettes diffère de celui de Petite-Rivière et du secteur de Québec-haut estuaire ainsi que de la rive sud. Ceci est probablement attribuable aux événements géologiques propres à l'embouchure du Saguenay notamment à la déglaciation tardive (Dionne et Occhietti, 1996). Rappelons aussi qu'il s'agit d'une région sismiquement active et que ce facteur a déjà été évoqué par Goldthwait (1911a, p. 307-309). D'ailleurs, des indices d'activité néotectonique ont été mis en évidence à Petite-Rivière (Dionne, 1996b).

Selon Emery et Aubrey (1991, p. 203), dans le secteur de l'embouchure du Saguenay, le taux d'émersion des terres est différent de celui des secteurs avoisinants. II aurait été de $5,7 \mathrm{~mm}$ par an entre 1968 et 1980, alors qu'à Petite-Rivière et Baie-Saint-Paul il serait inférieur à $1 \mathrm{~mm}$ par an (Dohler et Ku, 1970; Vanicek et Hamilton, 1972).

Si l'on considère l'ensemble des dates disponibles pour les rives sud et nord du Saint-Laurent estuarien, on constate que respectivement $77,5 \%$ et de $72,5 \%$ des dates tombent dans une tranche d'âge comprise entre 1400 et 2700 ans BP. Si on utilise plutôt l'âge médian pour les sites pour lesquels il existe plus de trois dates au ${ }^{14} \mathrm{C}, 77,8 \%$ des dates tombent dans la tranche d'âge de 1400 à $2700 \mathrm{BP}$ pour la rive sud et 1800 à $2600 \mathrm{BP}$ pour la rive nord.

L'épisode de Mitis semble donc s'être étendu sur une période d'environ 1000 à 1500 ans. II faut cependant admettre qu'il est souvent difficile de départager ce qui appartient vraiment au Mitis de ce qui relève de la période postérieure, notamment dans les secteurs où la basse terrasse est constituée de dépôts intertidaux. Quoi qu'il en soit, il ne fait aucun doute que la terrasse Mitis est une forme littorale édifiée à l'Holocène supérieur, vraisemblablement après une petite remontée du niveau marin relatif (Dionne, 2001b), période au cours de laquelle la falaise composée de matériel meuble à Montmagny, Cap-Saint-Ignace et Saint-Vallier (anse de Bellechasse) a été érodée (Dionne, 1988b, 1997, 2000). Dans d'autres localités, la falaise morte faite de matériel meuble, notamment d'argile, 
TABLEAU III

Dates au ${ }^{14} \mathrm{C}$ pour la terrasse Mitis

\begin{tabular}{|c|c|c|c|c|c|}
\hline Localité & Âge BP & No lab. & Type de matériel & Faciès ou dépôt & Référence \\
\hline \multicolumn{6}{|c|}{ A. Région de Québec et haut estuaire } \\
\hline Champlain & $\begin{array}{l}2020 \pm 70 \\
2180 \pm 60\end{array}$ & $\begin{array}{l}\text { UL-2239 } \\
\text { GSC-6304 }\end{array}$ & $\begin{array}{l}\text { Bois } \\
\text { Bois }\end{array}$ & $\begin{array}{l}\text { Littoral vs intertidal } \\
\text { Littoral vs intertidal }\end{array}$ & $\begin{array}{l}\text { Dionne, inédit } \\
\text { Bolduc, } 1999\end{array}$ \\
\hline Deschambault & $\begin{array}{l}1990 \pm 60 \\
2110 \pm 60\end{array}$ & $\begin{array}{l}\text { Beta-48531 } \\
\text { Beta-47287 }\end{array}$ & $\begin{array}{l}\text { Bois } \\
\text { Bois }\end{array}$ & $\begin{array}{l}\text { Littoral vs intertidal } \\
\text { Littoral vs intertidal }\end{array}$ & $\begin{array}{l}\text { Dionne, inédit } \\
\text { Dionne, inédit }\end{array}$ \\
\hline $\begin{array}{l}\text { Québec : } \\
\text { - Place Royale }\end{array}$ & $\begin{array}{l}1970 \pm 80 \\
1990 \pm 60 \\
2120 \pm 60\end{array}$ & $\begin{array}{c}\text { UL-575 } \\
\text { Beta-28462 } \\
\text { Beta-28259 }\end{array}$ & $\begin{array}{l}\text { Charbon de bois } \\
\text { Charbon de bois } \\
\text { Charbon de bois }\end{array}$ & $\begin{array}{l}\text { Plage } \\
\text { Plage } \\
\text { Plage }\end{array}$ & Allard et Séguin, 1992 \\
\hline - Rivière Saint-Charles & $2080 \pm 60$ & Beta-33922 & Bois & Plage & Garneau, 1997 \\
\hline Saint-Joachim & $2030 \pm 80$ & UL-1706 & Bois & Intertidal & Dionne, inédit \\
\hline \multicolumn{6}{|c|}{ B. Rive sud du Saint-Laurent } \\
\hline Rivière Boyer & $1980 \pm 50$ & UQ-601 & Bois & Interdidal (?) & Dionne, 1985b \\
\hline Anse de Bellechasse & $1450 \pm 70$ & UL-1563 & Bois & Alluvions & Dionne, 1997 \\
\hline Grosse-Île & $\begin{array}{l}2180 \pm 70 \\
2660 \pm 60\end{array}$ & $\begin{array}{l}\text { Beta-161229 } \\
\text { Beta-166030 }\end{array}$ & $\begin{array}{l}\text { Charbon de bois } \\
\text { Charbon de bois }\end{array}$ & $\begin{array}{l}\text { Plage } \\
\text { Plage }\end{array}$ & $\begin{array}{l}\text { Plourde, 2003, inédit } \\
\text { Plourde, 2003, inédit }\end{array}$ \\
\hline Montmagny & $2930 \pm 60$ & Beta-33772 & Bois & Intertidal & Dionne, 1998 \\
\hline La Pocatière & $1850 \pm 90$ & QU-188 & Débris organiques & Sol & Martel et Lasalle, 1977 \\
\hline Rivière-Ouelle & $\begin{array}{l}1470 \pm 80 \\
1800 \pm 60 \\
1830 \pm 60\end{array}$ & $\begin{array}{c}\text { UL-472 } \\
\text { UL-362 } \\
\text { Beta-28373 }\end{array}$ & $\begin{array}{l}\text { Bois } \\
\text { Bois } \\
\text { Bois }\end{array}$ & $\begin{array}{l}\text { Intertidal } \\
\text { Intertidal } \\
\text { Intertidal }\end{array}$ & $\begin{array}{l}\text { Dionne, 2001d } \\
\text { Bélanger, 1993 } \\
\text { Dionne, 2001d }\end{array}$ \\
\hline Kamouraska & $\begin{array}{l}1360 \pm 70 \\
1530 \pm 60\end{array}$ & $\begin{array}{l}\text { Beta-38082 } \\
\text { UL-1635 }\end{array}$ & $\begin{array}{l}\text { Bois } \\
\text { Bois }\end{array}$ & $\begin{array}{l}\text { Intertidal } \\
\text { Intertidal }\end{array}$ & $\begin{array}{l}\text { Dionne, inédit } \\
\text { Dionne, inédit }\end{array}$ \\
\hline Andréville & $1775 \pm 145$ & GX-9104 & Coquillages & Intertidal & Champagne et al., 1983 \\
\hline $\begin{array}{l}\text { Le Portage-Ouest } \\
\text { (riv. des Caps) }\end{array}$ & $1420 \pm 80$ & UL-679 & Débris organiques & Intertidal & Dionne, inédit \\
\hline Le Portage-Est & $3160 \pm 70$ & UL-283 & Coquillages & Plage & Bélanger, 1993 \\
\hline Rivière-du-Loup & $\begin{array}{l}2550 \pm 60 \\
2780 \pm 60\end{array}$ & $\begin{array}{l}\text { Beta-27671 } \\
\text { UL-288 }\end{array}$ & $\begin{array}{l}\text { Bois } \\
\text { Bois }\end{array}$ & $\begin{array}{l}\text { Intertidal } \\
\text { Intertidal }\end{array}$ & $\begin{array}{l}\text { Bélanger, } 1993 \text { et } \\
\text { Dionne, } 1990\end{array}$ \\
\hline Cacouna & $2420 \pm 65$ & UQ-612 & Bois & Intertidal & Bertrand, 1984 \\
\hline Isle-Verte & $\begin{array}{l}1430 \pm 90 \\
1430 \pm 70 \\
1480 \pm 60 \\
1490 \pm 90 \\
1620 \pm 70 \\
1990 \pm 70\end{array}$ & $\begin{array}{c}\text { Beta-26499 } \\
\text { UL-1715 } \\
\text { UL-1713 } \\
\text { UQ-613 } \\
\text { UL-1537 } \\
\text { UQ-560 }\end{array}$ & $\begin{array}{c}\text { Débris de plantes } \\
\text { Débris organiques } \\
\text { Bois } \\
\text { Bois } \\
\text { Bois } \\
\text { Mya arenaria }\end{array}$ & $\begin{array}{l}\text { Intertidal } \\
\text { Alluvial } \\
\text { Intertidal } \\
\text { Intertidal } \\
\text { Intertidal } \\
\text { Intertidal }\end{array}$ & $\begin{array}{l}\text { Garneau, } 1998 \\
\text { Dionne, } 1999 \\
\text { Dionne, } 1999 \\
\text { Bertrand, } 1984 \\
\text { Dionne, } 1999 \\
\text { Bertrand, } 1984\end{array}$ \\
\hline Cap-à-l'Orignal & $\begin{array}{l}2700 \pm 120 \\
2890 \pm 130\end{array}$ & $\begin{array}{l}\text { QU-444 } \\
\text { QU-603 }\end{array}$ & $\begin{array}{l}\text { Charbon de bois } \\
\text { Charbon de bois }\end{array}$ & $\begin{array}{l}\text { Plage } \\
\text { Plage }\end{array}$ & $\begin{array}{l}\text { Dumais, } 1978 \\
\text { Dumais, } 1978\end{array}$ \\
\hline Bic (cap Enragé) & $\begin{array}{l}2580 \pm 90 \\
2700 \pm 90\end{array}$ & $\begin{array}{l}\text { UL-1947 } \\
\text { UL-1915 }\end{array}$ & $\begin{array}{c}\text { Macoma balthica } \\
\text { Mya arenaria }\end{array}$ & $\begin{array}{l}\text { Plage } \\
\text { Plage }\end{array}$ & $\begin{array}{l}\text { Dionne, 2001c } \\
\text { Dionne, 2001c }\end{array}$ \\
\hline Pointe-au-Père & $1780 \pm 70$ & UL-1576 & Coquillages & Littoral & Hétu, inédit \\
\hline Baie-des-Sables & $2240 \pm 140$ & QU-265 & Mesodesma arctatum & Plage & Locat, 1977 \\
\hline Matane & $\begin{array}{l}1830 \pm 70 \\
2250 \pm 40^{*} \\
2260 \pm 110 \\
2380 \pm 90\end{array}$ & $\begin{array}{l}\text { UL-858 } \\
\text { TO-4305 } \\
\text { QU-152 } \\
\text { QU-146 }\end{array}$ & $\begin{array}{c}\text { Mesodesma arctatum } \\
\text { Mesodesma arctatum } \\
\text { Mya sp. } \\
\text { Coquillages }\end{array}$ & $\begin{array}{l}\text { Plage } \\
\text { Plage } \\
\text { Plage } \\
\text { Plage }\end{array}$ & $\begin{array}{l}\text { Dionne et Coll, } 1995 \\
\text { Dionne et Coll, } 1995 \\
\text { Lebuis et David, } 1977 \\
\text { Lebuis et David, } 1977\end{array}$ \\
\hline Sainte-Anne-des-Monts & $\begin{array}{l}1710 \pm 70 \\
1950 \pm 110\end{array}$ & $\begin{array}{l}\text { UL-2047 } \\
\text { UL-2074 }\end{array}$ & $\begin{array}{l}\text { Mesodesma arctatum } \\
\text { Mesodesma arctatum }\end{array}$ & $\begin{array}{l}\text { Plage } \\
\text { Plage }\end{array}$ & $\begin{array}{l}\text { Dionne, inédit } \\
\text { Dionne, inédit }\end{array}$ \\
\hline
\end{tabular}


TABLEAU III (suite)

Dates au ${ }^{14} \mathrm{C}$ pour la terrasse Mitis

\begin{tabular}{|c|c|c|c|c|c|}
\hline Localité & Âge BP & No lab. & Type de matériel & Faciès ou dépôt & Référence \\
\hline Mont-Louis & $2390 \pm 70$ & Beta-34763 & Mesodesma arctatum & Plage & Gray, inédit \\
\hline Mont-Saint-Pierre & $1630 \pm 55$ & DIC-1276 & Os de baleine & Plage & Gray et Hétu, inédit \\
\hline Rivière-Madeleine & $\begin{array}{l}2790 \pm 60 \\
2870 \pm 90 \\
2990 \pm 80 \\
3170 \pm 60\end{array}$ & $\begin{array}{c}\text { GSC-4580 } \\
\text { Beta-13856 } \\
\text { UL-1572 } \\
\text { Beta-13855 }\end{array}$ & $\begin{array}{l}\text { Mesodesma arctatum } \\
\text { Charbon de bois } \\
\text { Mesodesma arctatum } \\
\text { Mesodesma arctatum }\end{array}$ & $\begin{array}{l}\text { Plage } \\
\text { Plage } \\
\text { Plage } \\
\text { Plage }\end{array}$ & $\begin{array}{l}\text { Gray, inédit } \\
\text { Gray, } 1987 \\
\text { Hétu, inédit } \\
\text { Gray, } 1987\end{array}$ \\
\hline Grande-Vallée & $2680 \pm 80^{*}$ & UL-386 & Mytilus edulis & Plage & Lortie, inédit \\
\hline \multicolumn{6}{|c|}{ C. Côte nord du Saint-Laurent } \\
\hline Petite-Rivière & $\begin{array}{c}2000 \pm 50 \\
(n-24)\end{array}$ & Beta-38605 & Bois & Intertidal & Dionne, 1996b \\
\hline Pointe aux Alouettes & $\begin{array}{c}1370 \pm 50 \\
(n-25)\end{array}$ & Beta-28370 & Bois & Plage et intertidal & Dionne, 1996a \\
\hline Grandes-Bergeronnes & $2030 \pm 80$ & Beta-10819 & Bois & Intertidal & Daignault, 1984 \\
\hline $\begin{array}{l}\text { Pointe de Mille-Vaches } \\
\text { (Portneuf-sur-Mer) }\end{array}$ & $\begin{array}{c}1830 \pm 60 \\
(n-7)\end{array}$ & UL-1890 & Bois & Intertidal et littoral & $\begin{array}{l}\text { Dionne et Bernatchez, } \\
\text { inédit }\end{array}$ \\
\hline Betsiamites & $\begin{array}{c}2560 \pm 70 \\
(n-3)\end{array}$ & UL-1648 & Bois & Tourbe & $\begin{array}{l}\text { Dionne et Bernatchez, } \\
\text { inédit }\end{array}$ \\
\hline Ragueneau & $\begin{array}{c}1910 \pm 70 \\
(n-7)\end{array}$ & UL-1938 & Bois & Intertidal & $\begin{array}{l}\text { Dionne et Bernatchez, } \\
\text { inédit }\end{array}$ \\
\hline Pointe aux Outardes & $2190 \pm 70$ & UL-1725 & Bois & Littoral & $\begin{array}{l}\text { Dionne et Bernatchez, } \\
\text { inédit }\end{array}$ \\
\hline Pointe-Lebel & $2760 \pm 60$ & UL-1679 & Débris organiques & Littoral & $\begin{array}{l}\text { Dionne et Bernatchez, } \\
\text { inédit }\end{array}$ \\
\hline Blanc-Sablon & $2074 \pm 50$ & P-690 & Charbon de bois & Plage & Bigras et Dubois, 1987 \\
\hline
\end{tabular}

* Dates brutes non corrigées

N.B. : Les deux dates pour Grosse-Île m'ont été fournies par Michel Plourde ; elles ont été ajoutées au tableau après la soumission de l'article ; en conséquence, elles n'ont pas été comptabilisées dans les divers tableaux. La date de $2180 \pm 70$ BP corrrespond à l'âge médian de la terrasse Mitis.

\section{TABLEAU IV}

Âge au radiocarbone de la terrasse Mitis

\begin{tabular}{|c|c|c|c|c|c|}
\hline & \multirow{2}{*}{$\begin{array}{c}\text { Secteur A } \\
\text { Région de Québec } \\
\text { et haut estuaire }\end{array}$} & \multicolumn{2}{|c|}{$\begin{array}{c}\text { Secteur B } \\
\text { Côte sud (Saint-Vallier - Grande-Vallée) }\end{array}$} & \multicolumn{2}{|c|}{$\begin{array}{c}\text { Secteur C } \\
\text { Côte nord (haute Côte-Nord et Blanc-Sablon) }\end{array}$} \\
\hline & & Ensemble des dates & Avec les médianes* & Ensemble des dates & Avec les médianes \\
\hline Nombre de localités & 5 & 22 & 22 & 9 & 9 \\
\hline Nombre de dates $a u^{14} \mathrm{C}$ & 9 & 40 & 27 & 70 & 9 \\
\hline \multicolumn{6}{|l|}{ Âge BP : } \\
\hline minimal & $1970 \pm 80$ & $1360 \pm 70$ & $1360 \pm 70$ & $1110 \pm 50$ & $1370 \pm 50$ \\
\hline maximal & $2180 \pm 60$ & $3160 \pm 70$ & $3160 \pm 70$ & $2800 \pm 200$ & $2760 \pm 60$ \\
\hline médiane & $2030 \pm 80$ & $1980 \pm 50$ & $2240 \pm 40$ & $1910 \pm 70$ & $2030 \pm 80$ \\
\hline \multicolumn{6}{|l|}{ En pourcentage (\%) : } \\
\hline Entre 1500 et $2500 \mathrm{BP}$ & - & 47,5 & 48,2 & 60,9 & - \\
\hline Entre 1400 et $2600 \mathrm{BP}$ & - & 70,0 & 66,7 & 68,1 & - \\
\hline Entre 1400 et $2700 \mathrm{BP}$ & - & 77,5 & 77,8 & 72,5 & - \\
\hline Entre 1800 et $2600 \mathrm{BP}$ & 100 & 37,5 & 37,0 & 52,8 & 77,8 \\
\hline
\end{tabular}

* Âge basé sur la médiane pour les sites comprenant trois dates et plus. 
a probablement, elle aussi, été érodée pour une deuxième fois lors de l'épisode Mitis.

\section{CONCLUSION}

En conclusion, on retiendra que la ligne de rivage Micmac est une notion fort complexe puisqu'elle comprend trois éléments essentiels : une falaise morte, une basse terrasse (terrasse Mitis) et une batture correspondant à la zone intertidale actuelle, mais en continuité morphologique avec les deux autres éléments, et que ces composantes n'ont pas forcément le même âge.

L'âge médian de la basse terrasse est d'environ 2000 ans BP. La falaise rocheuse et la plate-forme adjacente, qui réapparaît dans la zone intertidale, constituent des éléments d'un relief ancien ou relique portant des traces du passage du dernier glacier, dont l'écoulement s'est fait vers le nord-est. Ces formes héritées ont cependant été retouchées au cours de l'Holocène par les agents littoraux et subaériens. La falaise composée de matériel meuble, que ce soit de l'argile marine ou glacio-marine ou d'autres dépôts quaternaires, a vraisemblablement été taillée en deux phases, soit lors de la transgression de l'Holocène moyen (Transgression laurentienne), soit juste avant l'édification de la basse terrasse.

La falaise Micmac correspond au talus de la troisième terrasse en bordure des rives du Saint-Laurent et non à la basse terrasse dénommée Mitis pour éviter la confusion. Désormais la distinction des trois composantes de la ligne de rivage Micmac de Goldthwait s'impose à quiconque cherche à comprendre et à expliquer les événements géologiques qui ont façonné les rives du Saint-Laurent estuarien.

Dans l'état actuel des connaissances, il demeure difficile de préciser les fluctuations du niveau marin relatif au cours des derniers millénaires, en particulier depuis la Transgression laurentienne. Si certains indices permettent de croire qu'il y a eu une petite fluctuation $( \pm 2 \mathrm{~m}$ ) correspondant au niveau Mitis, d'autres indices, par contre, favorisent plutôt une émersion progressive des terres durant la même période. Cette interrogation montre la nécessité de poursuivre les recherches sur le Quaternaire des rives du Saint-Laurent estuarien.

La ligne de rivage Micmac, un élément important du relief littoral du Saint-Laurent estuarien qui avait retenu l'attention de J. W. Goldthwait au début du XXe siècle, est désormais mieux connue. Elle constitue un bel exemple de géomorphologie complexe où formes héritées, récentes et actuelles, façonnées par divers agents forment un tout apparemment simple qui a cependant nécessité plusieurs années de recherche. Cette mise au point devrait permettre une meilleure compréhension des événements géologiques à l'origine de cette ligne de rivage particulière.

\section{REMERCIEMENTS}

La présente contribution fait partie d'un projet de recherche à long terme sur l'évolution des rives du Saint-Laurent estuarien subventionné par le Conseil de recherches en sciences naturelles et en génie (CRSNG), à Ottawa. Plusieurs dates au ${ }^{14} \mathrm{C}$ ont été réalisées au Laboratoire de radiochronologie du
Centre d'études nordiques de l'Université Laval. Le texte a été édité au secrétariat du Département de Géographie et par madame Pierrette Morissette, alors que les figures ont été réalisées par madame Andrée Gauthier du Laboratoire de carthographie du même département. L'auteur tient à remercier tous ceux et celles qui lui ont fourni des dates au ${ }^{14} \mathrm{C}$ inédites ou récemment publiées. Les travaux de Carl Bélanger (1993), de Pierre Bertrand (1984) et de Michelle Garneau (1984, 1998), anciens étudiants au Département de géographie de l'Université Laval, ont été fort utiles. L'auteur tient aussi à remercier les lecteurs critiques, Yves Michaud et Jean-Marie Dubois, ainsi que le rédacteur associé, Bernard Hétu, pour leurs remarques faites à la lecture du manuscrit.

\section{RÉFÉRENCES}

Allard, M., 1981. L'anse aux Canards, île d'Orléans, Québec : évolution holocène et dynamique actuelle. Géographie physique et Quaternaire, 35 : 133-154.

Allard, M. et Séguin, J., 1992. Le niveau du Saint-Laurent de 2000 BP et l'occupation amérindienne préhistorique de la Place Royale, à Québec. Géographie physique et Quaternaire, $46: 181-188$.

Beaubien, P., 1973. Contribution à la géographie physique de l'île d'Orléans. Thèse de maîtrise, Département de géographie, Université Laval, Québec, $130 \mathrm{p}$.

Bélanger, C., 1993. Étude géomorphologique des basses terrasses marines sur la côte sud de l'estuaire laurentien. Thèse de doctorat, Département de géographie, Université Laval, Québec, 222 p.

Bertrand, P., 1984, Le secteur côtier Cacouna - Isle-Verte : étude géomorphologique et classification des sols. Thèse de maîtrise, Département de géographie, Université Laval, Québec, 253 p.

Bigras, P. et Dubois, J.-M.M., 1987. Répertoire commenté des datations ${ }^{14} \mathrm{C} d u$ nord de l'estuaire et du golfe du Saint-Laurent, Québec et Labrador. Département de géographie, Université de Sherbrooke, Bulletin de recherche, 94-96,166 $\mathrm{p}$.

Bird, J.B., 1972. The denudational evolution of the Maritime Provinces, Canada. Revue de Géographie de Montréal, 26 : 421-432.

Blanchard, R., 1935. L'Est du Canada français. Beauchemin, Montréal, et Masson, Paris, $366 \mathrm{p}$.

Bolduc, A., 1999. Nouveau site de la transgression Mitis à Champlain, vallée du Saint-Laurent, Québec. Commission géologique du Canada, Ottawa, Recherches en cours 1999-E : 169-174.

Brodeur, D., 1982. Morphologie et histoire quaternaire de l'île aux Coudres. Thèse de maîtrise, Département de géographie, Université Laval, Québec, 256 p.

Brodeur, D. et Allard, M., 1983. Les plates-formes littorales de l'île aux Coudres, moyen estuaire du Saint-Laurent, Québec. Géographie physique et Quaternaire, $37: 179-195$

Champagne, P., Denis, R. et Lebel, C., 1983. Établissement de modèles carac térisant l'équilibre dynamique des estrans de la rive sud du moyen estuaire du Saint-Laurent. Rapport des sciences halieutiques et aquatiques 1711, Pêches et Environnement Canada, Québec, 67 p.

Daignault, R.A., 1984. Cadre géologique des sites archéologiques DbFj-11 et DbEj-13 de Grandes-Bergeronnes (été 1984). Département des Sciences de la Terre, Université du Québec à Montréal, Rapport non publié, $34 \mathrm{p}$.

Daly, R.A., 1920. A recent world-wide sinking of ocean level. Geological Magazine, 57: 246-261.

Dawson, J.W., 1893. The Canadian Ice Age. William Dawson, Montréal, 301 p.

Deevey, E.S. et Flint, R.F., 1957. Postglacial hypsithermal interval. Science $125: 182-184$

Desaulniers, J.G. 1985. Les terrasses de la rive nord du Saint-Laurent entre Cap-Rouge et Donnacona. Mémoire de baccalauréat, Département de géographie, Université Laval, Québec, 89 p. 
Dionne, J.-C., 1963. Le problème de la terrasse et de la falaise MicMac. Revue canadienne de géographie, $17: 9-25$.

1970. Aspects morpho-sédimentologiques du glaciel, en particulier des côtes du Saint-Laurent. Environnement Canada, Laboratoire de recherches forestières des Laurentides, Québec, Rapport d'information Q-F-X-9, 324 p.

1972. La terrasse et la falaise Micmac, p. 34-38. In Le Quaternaire de la région de Rivière-du-Loup / Trois-Pistoles, côte sud de l'estuaire maritime du Saint-Laurent. Environnement Canada, Centre de recherches forestières des Laurentides, Québec, Rapport d'information Q-F-X-27, 95 p.

1977. La Mer de Goldthwait au Québec. Géographie physique et Quaternaire, $31: 61-80$.

1985a. Formes, figures et faciès sédimentaires glaciels des estrans vaseux des régions froides. (In M. Deynoux, édit., Glacial record). Paleo, 51 : 415-451.

1985b. Observations sur le Quaternaire de la rivière Boyer, Côte sud de l'estuaire du Saint-Laurent, Québec. Géographie physique et Quaternaire, $39: 35-46$.

1987. Lithologie des cailloux de la baie de Montmagny, côte sud du SaintLaurent. Géographie physique et Quaternaire, $41: 161-169$.

1988a. L'émersion de la côte sud du Saint-Laurent depuis la dernière glaciation. Geos, $17: 18-21$.

1988b. Holocene relative sea-level fluctuations in the St. Lawrence estuary, Québec, Canada. Quaternary Research, 29 : 233-244.

1988c. Characteristics features of modern tidal flats in cold regions, p. 301332. In P.L. de Boer, A. van Gelder et S.D. Nio, édit., Tide-influenced Sedimentary Environments and Facies. Reidel, Dordrecht, $530 \mathrm{p}$.

1990. Observations sur le niveau marin relatif à l'Holocène, à Rivière-duLoup, estuaire du Saint-Laurent, Québec, Géographie physique et Quaternaire, $44: 43-53$.

1992a. État des connaissances sur la terrasse Mitis : ligne de rivage Micmac de Goldthwait. $7^{\mathrm{e}}$ Congrès quadriennal de l'AQQUA (RouynNoranda), Bulletin de l'AQQUA, $18: 32-33$.

1992b. Aperçu géomorphologique de l'île aux Lièvres et des îlots environnants, moyen estuaire du Saint-Laurent. Rapport soumis à la Société Duvetnor, Département de géographie, Université Laval, Québec, 56 p.

1993. The twenty-foot terrace and sea cliff of the Lower St. Lawrence. Geological Society of America. Annual Meeting (Boston, 25-28 octobre), Abstracts with Programs, 25 (6), A-124.

1996a. La terrasse Mitis à la pointe aux Alouettes, côte nord du moyen estuaire du Saint-Laurent. Géographie physique et Quaternaire, 50 : 57-72.

1996b. La basse terrasse à Petite-Rivière (Charlevoix) : un exemple d'activité néo-tectonique à l'Holocène. Géographie physique et Quaternaire, $50: 311-330$.

1997. Nouvelles données sur la Transgression laurentienne, côte sud du moyen estuaire du Saint-Laurent, Québec. Géographie physique et Quaternaire, $51: 199-208$

1998. Relative sea-level variations during the Holocene, middle St. Lawrence estuary. Geological Association of Canada, Annual Meeting (Québec, 18-21 mai), Field Trip B1 Guidebook, Québec, 49 p.

1999. Indices de fluctuations mineures du niveau marin relatif à l'Holocène supérieur à L'Isle-Verte, côte sud de l'estuaire du Saint-Laurent, Québec. Géographie physique et Quaternaire, 53 :277-285.

2000. Données complémentaires sur les variations du niveau marin relatif à l'Holocène, à l'anse de Bellechasse, sur la côte sud du moyen estuaire du Saint-Laurent. Géographie physique et Quaternaire, 54 : 119-122.

2001a. Traces du dernier épisode glaciaire à l'île aux Lièvres, estuaire du Saint-Laurent. Le Naturaliste canadien, 125 : 43-48.

2001b. Relative sea-level changes in the St. Lawrence estuary from deglaciation to present day, p. 271-284. In T. K. Weddle et M. J. Retelle, édit., Deglacial History and Relative Sea-level Changes, Northern New England and Adjacent Canada. Geological Society of America, Boulder, Special Paper 351, $292 \mathrm{p}$.

2001c. Le tombolo du cap Enragé, parc du Bic, Bas-Saint-Laurent. Géographie physique et Quaternaire, 55 : 185 - 195. 2001d. Fluctuations holocènes du niveau marin relatif à Rivière-Ouelle, côte sud du moyen estuaire du Saint-Laurent : données complémentaires. Géographie physique et Quaternaire, 55 : 289-300.

2002a. Les erratiques de dolomie à Rivière-Blanche, côte sud de l'estuaire maritime du Saint-Laurent : un indicateur de transport glaciaire et glaciel. Canadian Journal of Earth Science, 39 : 1239-1255.

2002b. The boulder barricade at Cap à la Baleine, North shore of Gaspé Peninsula (Québec): nature of boulders, origin and significance. Journal of Coastal Research, 18 : 652-661.

Dionne, J.-C. et Brodeur, D., 1988a. Érosion des plates-formes rocheuses littorales par affouillement glaciel. Zeitschrift für Geomorphologie, 32 : 101-115.

1998b. Frost weathering and ice action in shore platform development, with particular reference to Québec, Canada. Zeitschrift für Geomorphologie, Supplementband, $71: 117-130$.

Dionne, J.-C. et Coll, D., 1995. Le niveau marin relatif dans la région de Matane (Québec), de la déglaciation à nos jours. Géographie physique et Quaternaire, $49: 363-380$

Dionne, J.-C. et Occhietti, S., 1996. Aperçu du Quaternaire à l'embouchure du Saguenay. Géographie physique et Quaternaire, $50: 5-34$.

Dionne, J.-C. et Poitras, S., 1996. Observations géomorphologiques sur la batture à méga-blocs, à Petite-Rivière, Charlevoix, Québec. Géographie physique et Quaternaire, 50 : 221-232.

1998. Lithologie des cailloux de la baie de Mitis, rive sud de l'estuaire maritime du Saint-Laurent (Québec) : un exemple de transport glaciaire et glaciel complexe. Géographie physique et Quaternaire, 52 : 107-122.

Dohler, G.C. et Ku, L.F., 1970. Presentation and assessment of tides and water level records for geophysical investigations. Canadian Journal of Earth Sciences, $7: 607-625$.

Dubois, J.-M.M., 1980. Géomorphologie du littoral de la Côte Nord du SaintLaurent : analyse sommaire, p. 215-238. In S. B. McCann, édit., The Coastline of Canada. Geological Survey of Canada, Ottawa, Paper 80-10, $439 \mathrm{p}$.

Dumais, P., 1978. Rapport préliminaire de la fouille des sites DbEf-4, DcEe-2, DcEe-3B et de la reconnaissance de la rivière du Sud-Ouest, parc provincial du Bic, été 1978. Service d'archéologie et d'ethnologie, Ministère des Affaires culturelles, Québec, Rapport manuscrit, $116 \mathrm{p}$.

Duncan, M., 1981. La genèse géomorphologique de Kamouraska nord-ouest. Thèse de maîtrise, Département de géographie, Université Laval, Québec, $140 \mathrm{p}$.

Emery, K.O. et Aubrey, D.G., 1991. Sea Levels, Land Levels, and Tide Gauges. Springer-Verlag, New York, $237 \mathrm{p}$.

Gadd, N.R., 1971. Pleistocene Geology of the central St. Lawrence Lowlands. Geological Survey of Canada, Ottawa, Mémoire 359, 153 p.

Garneau, M., 1987. Reconstitution paléoécologique d'une tourbière littorale de l'estuaire du Saint-Laurent : analyse macrofossile et sporopollinique. Géographie physique et Quaternaire, 41 : 109-125.

1997. Paléoécologie d'un secteur riverain de la rivière Saint-Charles : analyse macro-fossile du site archéologique de la Grande Place, à Québec. Géographie physique et Quaternaire, 51 : 211-220.

1998. Paléoécologie d'une tourbière littorale de l'estuaire maritime du Saint-Laurent, Isle-Verte, Québec. Commission géologique du Canada, Ottawa, Bulletin 514, $149 \mathrm{p}$.

Goldthwait, J.W., 1911a. The twenty-foot terrace and sea cliff of the Lower St. Lawrence. American Journal of Science, 32 : 291-317.

1911b. Raised beaches of southern Québec, p. 220-233. In Geological Survey of Canada, Summary Report- 1910.

1913. Excursion in eastern Québec and the Maritimes Provinces. Part 1. Guide Book no. 1, International Geological Congress (Ottawa). (ligne de rivage Micmac : p. 48-51;77-81).

1933. The St. Lawrence Lowland. Geological Survey of Canada, manuscrit non publié, $192 \mathrm{p}$. 
Grant, D.R., 1980. Quaternary sea-level change in Atlantic Canada as an indication of crustal delevelling, p. 201-214. In N.A. Morner, édit., Earth Rheology, Isostasy and Eustasy. John Wiley, London, 599 p.

1989. Le Quaternaire de la région des Appalaches atlantiques du Canada, p. 421-474. In R.J. Fulton, édit., Le Quaternaire du Canada et du Groenland, Commission géologique du Canada, Ottawa, Série géologie du Canada, vol. 1, $907 \mathrm{p}$.

1992. Quaternary Geology of St. Antony-Blanc-Sablon Area Newfoundland and Québec. Geological Survey of Canada, Ottawa, Mémoire 427, $60 \mathrm{p}$.

Gray, J.T., édit., 1987. Processus et paléo-environnements du Quaternaire dans la péninsule gaspésienne et au Bas-Saint-Laurent. Livret-guide Excursion C-4, XII ${ }^{\text {e }}$ Congrès international de l'INQUA, Ottawa, 85 p.

Harmon, R.S., Land, L.S., Mitterer, R. M., Garrett, P., Schwarcz, H. P. et Larson, G. J., 1981. Bermuda sea level during the last interglacial. Nature, 289 : 481-483.

Henderson, E.P., 1972. Surficial Geology of Avalon Peninsula, Newfoundland. Geological Survey of Canada, Ottawa, Mémoire 368,121 p.

Hétu, B., 1994. Déglaciation, émersion des terres et pergélisol dans la région de Rimouski, Québec. Paléo-Québec, 22 : 4-48.

Hétu, B. et Gray, J.T., 2000. Les étapes de la déglaciation dans le nord de la Gaspésie (Québec) : les marges glaciaires des Dryas ancien et récent. Géographie physique et Quaternaire, 54 : 5-20.

Hocq, M. et Martineau, G., 1994. Le Quaternaire, p. 121-128. In C. Dubé, édit., Géologie du Québec. Les Publications du Québec, Québec, 154 p.

Johnson, D.W., 1925. The New England Acadian Shoreline. John Wiley, New York, $608 \mathrm{p}$

Karrow, P.F., 1959. Surficial geology, Grondines, Québec. Geological Survey of Canada, Map 41-1959 (avec texte).

Lagarec, D., 1971. L'évolution des versants d'une partie de la colline de Québec. Thèse de maîtrise, Département de géographie, Université Laval, Québec, $127 \mathrm{p}$.

LaSalle, P., 1972. Interglacial sediments in the Quebec City Area. International Geological Congress (Montréal), Abstracts, 24 : 372-373.

1984. Quaternary stratigraphy of Quebec : A review, p. 155-171. In R.J. Fulton, édit., Quaternary Stratigraphy of Canada - A Canadian Contribution to IGCP 24. Geological Survey of Canada, Ottawa, Paper 84-10, 210 p.

1987. Introduction à la géologie du Quaternaire de la région de Québec p. 10-15. In J.T. Gray, édit., Processus et paléo-environnements du Quaternaire dans la péninsule gaspésienne et au Bas-Saint-Laurent. Livret Guide Excursion C-4, XII Congrès international de l'INQUA, Conseil national de recherche du Canada, Ottawa, $85 \mathrm{p}$.

LaSalle, P., Martineau, G. et Chauvin, L., 1977. Morphologie, stratigraphie et déglaciation dans la région de Beauce - Monts Notre-Dame - Parc des Laurentides. Ministère des Richesses naturelles, Québec, Rapport DPV 516, 76 p. (bilingue).
Lebuis, J. et David, P.P. 1977. La stratigraphie et les événements du Quaternaire de la partie occidentale de la Gaspésie, Québec. Géographie physique et Quaternaire, $31: 275-296$

Livernoche, C., Bail, P. et Hétu, B., 1985. Les plates-formes littorales étagées de la région de Mont-Louis, Gaspésie septentrionale, p. 46-61. In Actes du Congrès, Association canadienne des géographes, Trois-Rivières.

Locat, J., 1976. Quaternary geology of Baie-des-Sables / Trois-Pistoles area, Quebec; with some emphasis on the Goldthwait Sea clays. Thèse M.Sc., Department of Earth Sciences, Waterloo University, 214 p.

1977. L'émersion des terres dans la région de Baie-des-Sables - TroisPistoles, Québec. Géographie physique et Quaternaire, 31 :297-306.

1978. Le Quaternaire de la région de Baie-des-Sables / Trois-Pistoles. Ministère des Richesses naturelles, Québec. Rapport DPV 605, 64 p.

Logan, W., 1863. Geology of Canada. Geological Survey of Canada, Report of Progress from its commencement to 1863. Dawson Brothers, Montréal, $983 \mathrm{p}$.

Lougee, R.J., 1953. A chronology of Postglacial time in eastern North America. Scientific Monthly, 76 : 259-276.

Lougee, R.J. et Lougee, C.R., 1976. Late-glacial Chronology. Vantage Press, New York, $553 \mathrm{p}$.

Marshall, J.F. et Thom, B.G., 1976. The sea level in the last interglacial. Nature, $263: 120-121$

Martel, Y.A. et LaSalle, P., 1977. La datation au radiocarbone de la matière organique de quelques sols du Québec. Géographie physique et Quaternaire, $31: 373-378$.

McGerrigle, H.W., 1959. Les régions de Tourelle et de Courcelette, péninsule de Gaspé. Ministère des mines, Québec, Rapport géologique 62, 76 p.

Occhietti, S., 1989. Géologie quaternaire de la sous-région de la vallée du SaintLaurent et des Appalaches, p. 374-407. In R. J. Fulton, édit., Le Quaternaire du Canada et du Groenland. Commission géologique du Canada, Ottawa, Série géologie du Canada, vol. 1, $907 \mathrm{p}$.

Sabourin, R.J.E., 1963. Notes sur la géomorphologie d'une partie de la Côte de Beaupré. Cahiers de Géographie de Québec, 7 :27-36.

Stea, R.R., édit., 1987. Quaternary glaciations, geomorphology and sea-level changes; Bay of Fundy Region. Field Trip Guide Book, North Atlantic Treaty Organization Advanced Course on Late-Quaternary Sea-level Correlations and Applications. Halifax, $79 \mathrm{p}$.

Vacher, H.L. et Hearty, P., 1989. History of stage 5 sea level in Bermuda : Review with new evidence of a brief rise to present sea level during substage $5 \mathrm{e}$. Quaternary Science Reviews, 43 : 161-178.

Vanicek, P. et Hamilton, A.C., 1972. Further analysis of vertical crustal movement observations in the Lake St. Jean area, Québec. Canadian Journal of Earth Sciences, $9: 1139-1147$. 


\section{ANNEXE}

\section{DIVERS ASPECTS DE LA LIGNE DE RIVAGE MICMAC}

Afin d'illustrer le caractère changeant de la ligne de rivage Micmac, nous avons sélectionné une dizaine de photographies aériennes montrant certains aspects particuliers de la morphologie du littoral de la rive sud de l'estuaire du Saint-Laurent. Cette partie complète l'information fournie dans le texte.

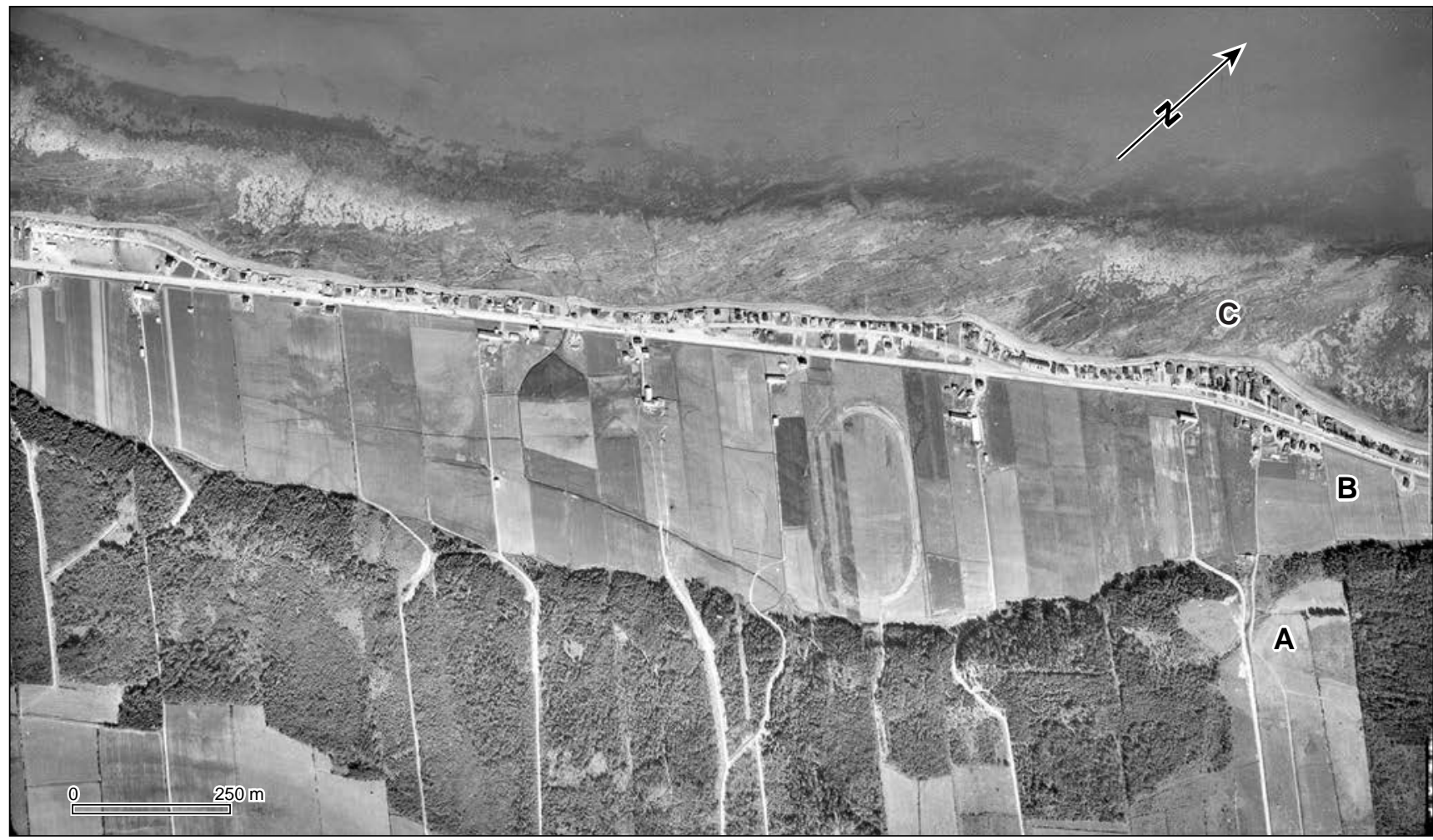

1. Composantes de la ligne de rivage Micmac du secteur à l'ouest de Sainte-Flavie, sur la côte sud de l'estuaire maritime du SaintLaurent. (A) falaise Micmac taillée dans de l'argile caillouteuse et dans du roc (schistes) dans la partie inférieure de l'escarpement; (B) terrasse Mitis, relativement large, constituée de sable et de gravier reposant sur une plate-forme rocheuse relique; (C) batture mixte, constituée à la fois par une plate-forme rocheuse et par un estran argileux caillouteux. Photographie aérienne verticale Q76 119-9, Photocartothèque québécoise, Québec.
The Micmac shoreline west of Sainte-Flavie, south shore of the Lower St. Lawrence estuary. (A) The Micmac cliff is cut into a stony marine clay overlying a low rock ridge. (B) The Mitis terrace, which is relatively wide, is made of sand and gravel (beaches) overlying a relict rock platform. (C) The tidal zone is made of a rock platform and a boulder-strewn clay surface. Vertical air photograph Q76 119-9, Photocartothèque québécoise, Québec.

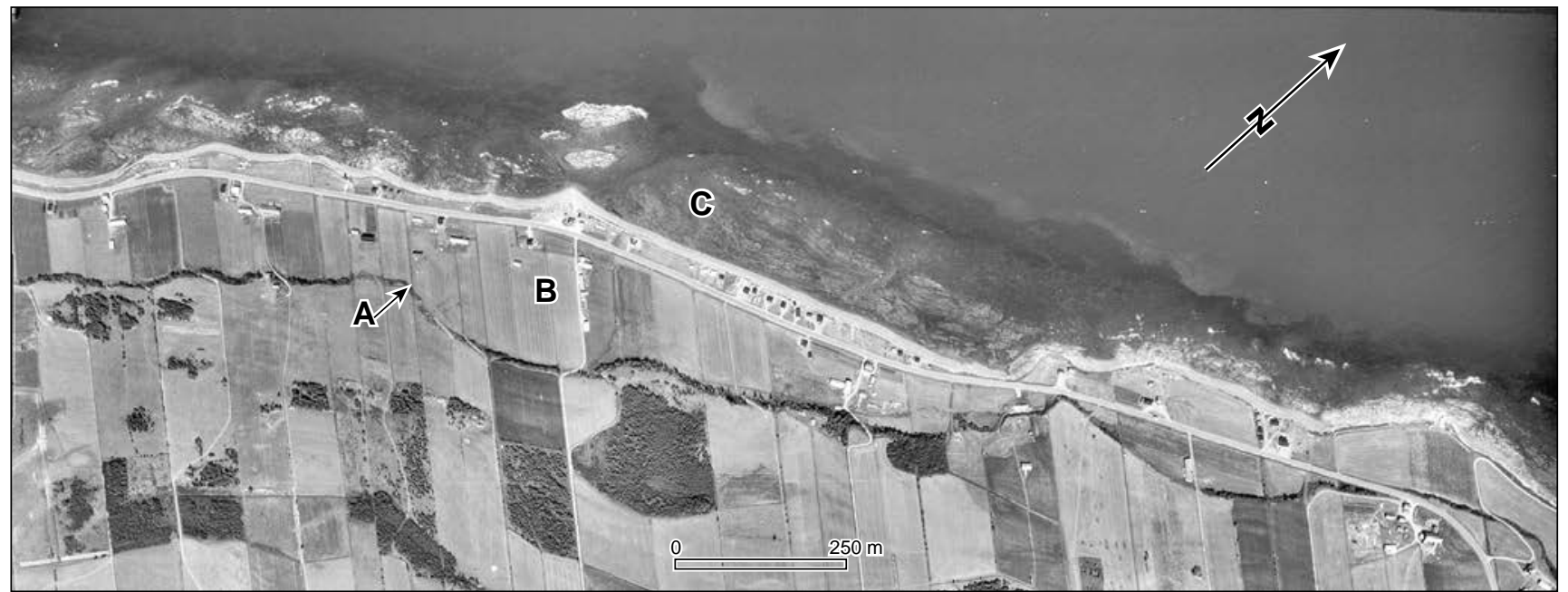

2. Ligne de rivage Micmac entre Sainte-Flavie et la pointe aux Cenelles (Mitis). (A) Tracé sinueux de la falaise Micmac principalement taillée dans le roc (schistes) mais aussi dans du matériel meuble pour la partie supérieure (plages de sable et gravier sur argile marine caillouteuse). Terrasse Mitis (B) moyennement large, constituée de sable et de gravier (plages) reposant sur une plate-forme rocheuse relique. Batture mixte (C) formée d'une plate-forme rocheuse et d'un estran argileux caillouteux. Photographie aérienne verticale Q76 117-228, Photocartothèque québécoise, Québec.
The Micmac shoreline between Sainte-Flavie and Pointe aux Cenelles (Mitis). The Micmac cliff ( $A$ ) is mainly cut into a bedrock ridge (slates) covered by a thin deposit of sand and gravel (beaches) overlying marine clay; the outline of the Micmac cliff is sinuous. The relatively narrow Mitis terrace $(B)$ is composed of sand and gravel overlying a relict rock platform. The tidal zone $(C)$ is composed of a rock platform with some areas cut into marine clay with boulder lags. Vertical air photograph Q76 117-228, Photocartothèque québécoise, Québec. 


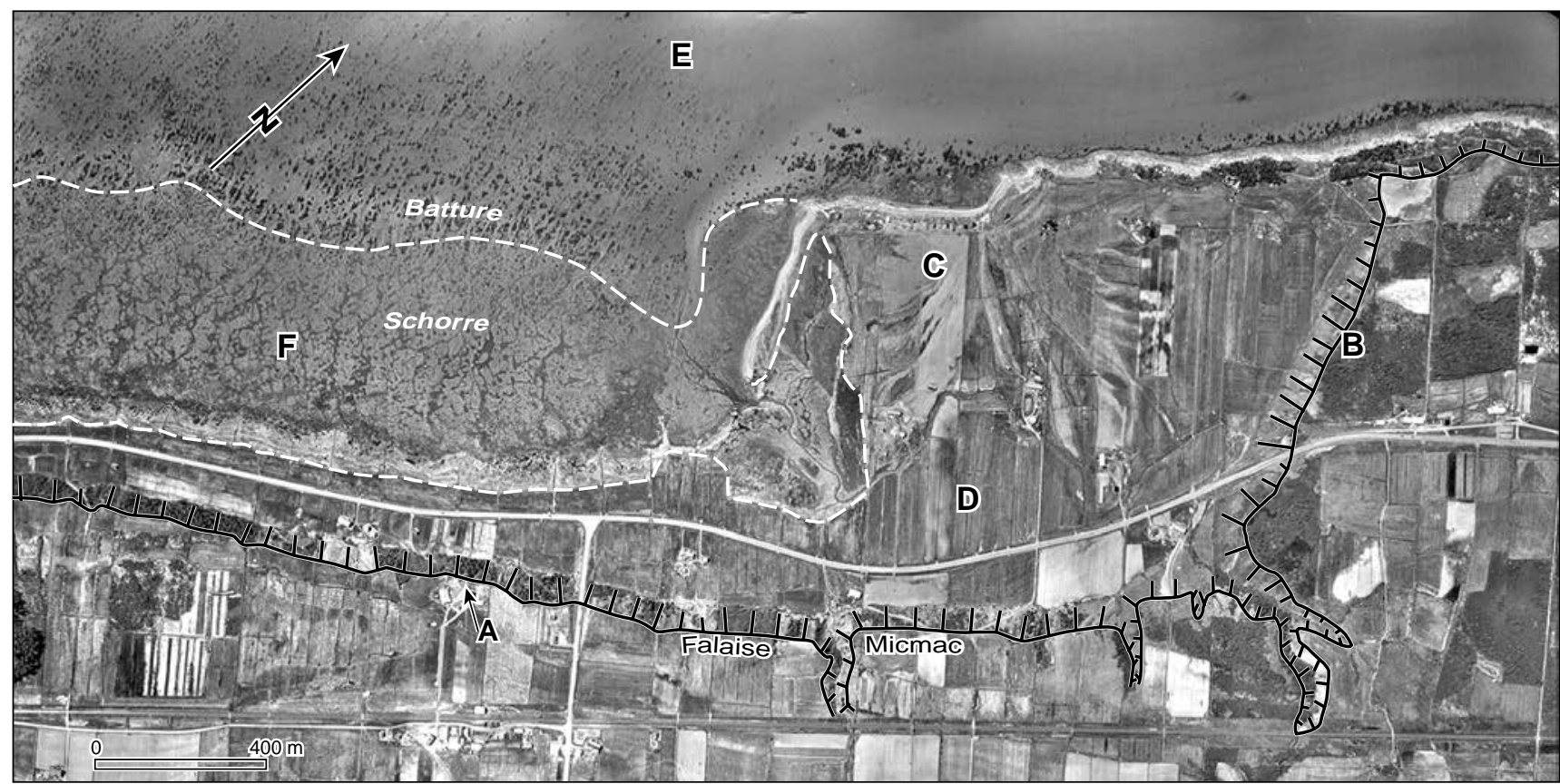

3. Tracé de la ligne de rivage Micmac à la pointe à la Loupe (Isle-Verte est). Le secteur rectiligne de la falaise Micmac (A) est parallèle au rivage; l'escarpement est taillé dans de l'argile caillouteuse qui recouvre une crête rocheuse. On voit plusieurs cordons littoraux (plages) à la surface des terrasses. Dans la partie est de la photographie, la falaise Micmac (B) est entièrement en argile et la falaise, orientée vers le SO, est située relativement loin du rivage actuel. Sur la basse terrasse, on observe une flèche $(\mathrm{C})$ à crochets multiples (flèche Papillon). La terrasse Mitis (D) consiste en un dépôt intertidal limoneux reposant sur une surface argileuse, excepté dans le secteur de la flèche littorale. La batture argileuse (E) dont on voit seulement une petite partie du marais intertidal (F) mesure environ $2 \mathrm{~km}$ de largeur. Photographie aérienne verticale Q63 305-125, Photocartothèque québécoise, Québec.
The Micmac shoreline at Pointe à la Loupe (east of Isle-Verte). Parallel to the present shoreline, the main section of the Micmac cliff $(A)$ is cut into bedrock overlaid by a thin sandy deposit (beaches) and marine clay; the section to the right $(B)$ is entirely cut into marine clay, oriented to SW, and relatively far from the modern shoreline. There is a butterfly-like spit of sand and gravel (C) on the low terrace (Mitis); elsewhere, the Mitis terrace $(D)$ is made of a thin silty intertidal deposit overlying a clay substrate. A clay tidal flat $(E)$ including a narrow marsh $(F)$ extends seaward up to $2 \mathrm{~km}$ in front of the Mitis terrace. Vertical air photograph Q63 305-125, Photocartothèque québécoise, Québec.

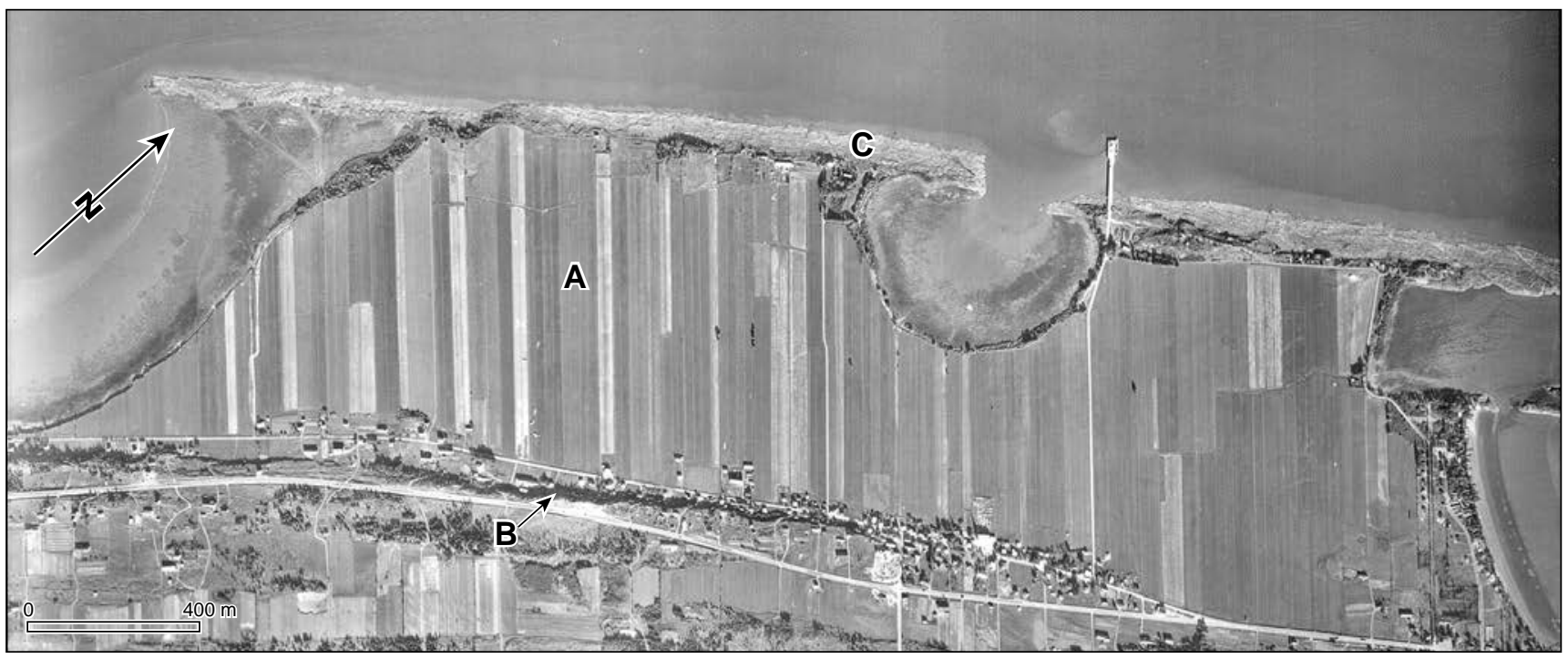

4. La terrasse Mitis à Berthier-sur-Mer. La terrasse Mitis $(A)$ d'environ $800 \mathrm{~m}$ de largeur occupe une dépression entre deux crêtes rocheuses. Elle est formée d'un dépôt intertidal limoneux de un à deux mètres d'épaisseur recouvrant une surface argileuse. La falaise Micmac $(B)$ correspond à une crête rocheuse (schistes) parallèle au rivage ; on voit aussi une crête rocheuse aplanie $(C)$ en bordure du rivage actuel. Photographie aérienne verticale 6131-142, Photocartothèque québécoise, Québec.
The Mitis terrace at Berthier-sur-Mer. Approximately $800 \mathrm{~m}$ wide, the low terrace $(A)$ occupies a depression between two rock ridges. It is composed of a silty intertidal deposit (1-2 m) overlying a clay substrate. The Micmac cliff $(B)$ is cut into bedrock (slates) and is parallel to the shoreline; a narrow levelled rock ridge (C) outcrops on the modern shoreline. Vertical air photograph 6132-142, Photocartothèque québécoise, Québec. 


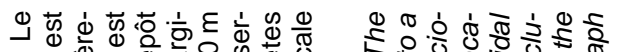

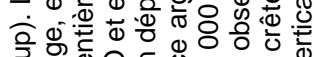

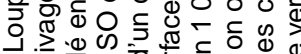

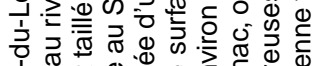

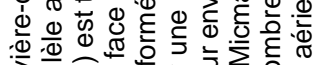

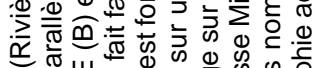

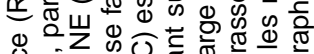

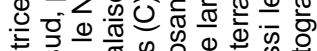

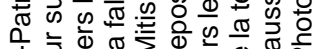

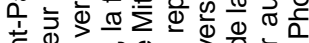

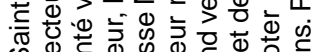

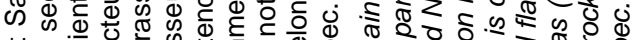

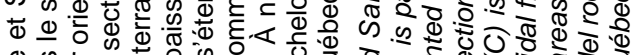

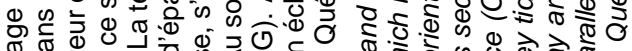
元 $\frac{0}{0}$ 过

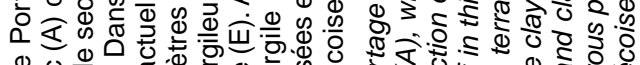

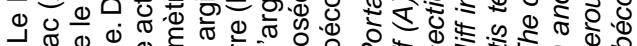

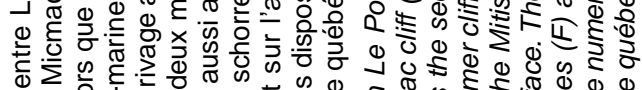

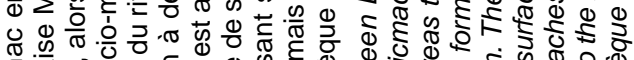

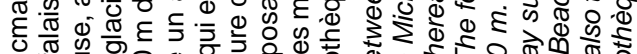

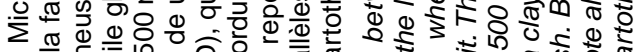

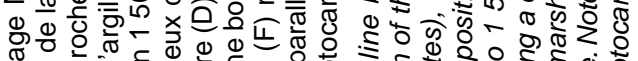

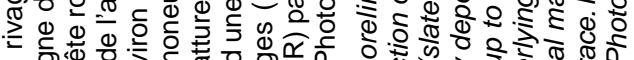
\&.

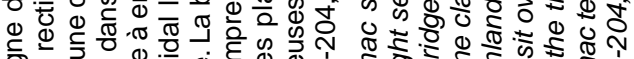

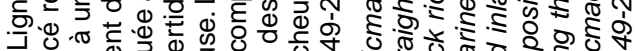
ம்

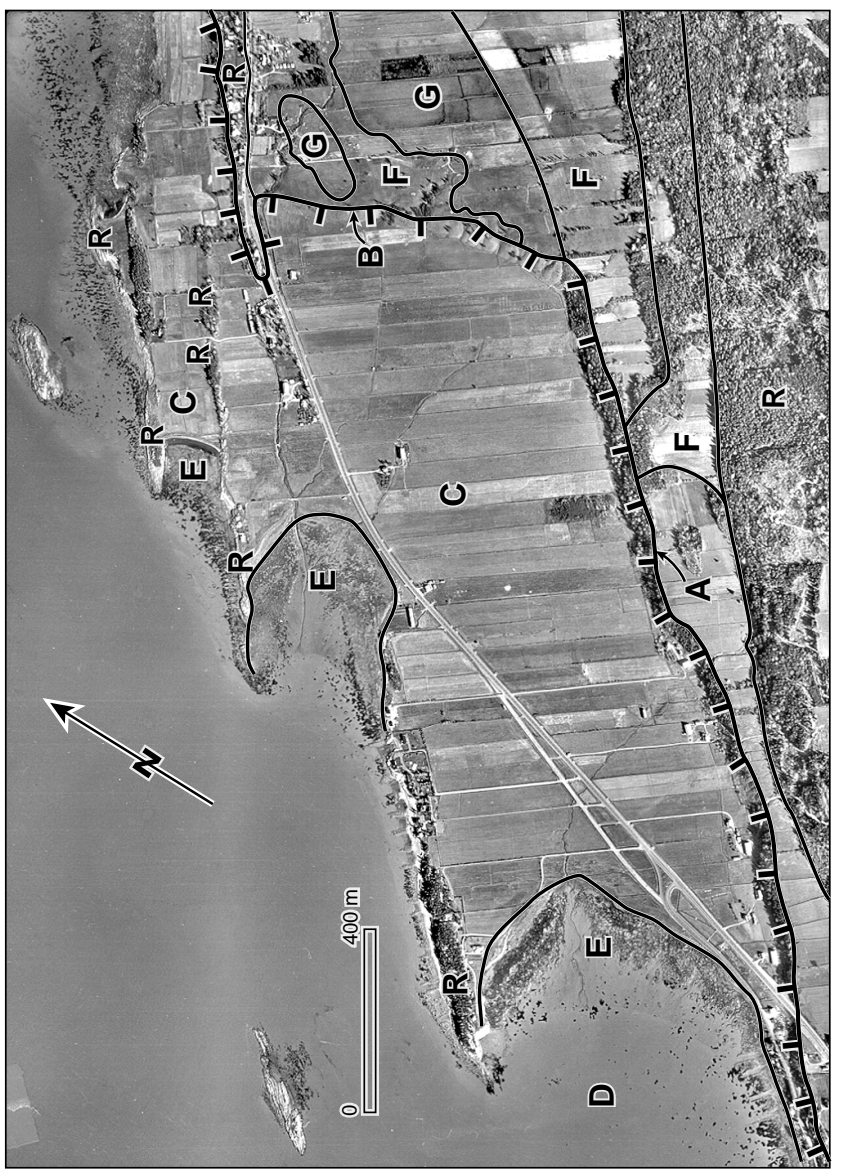

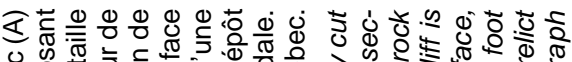

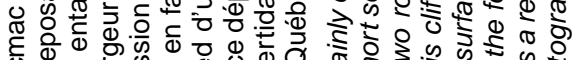

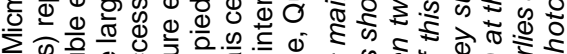
o 8

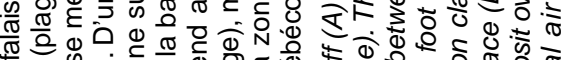

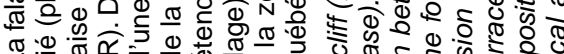

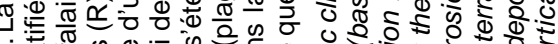

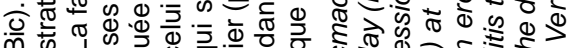

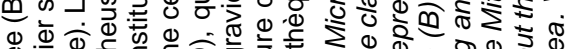

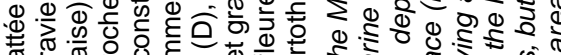

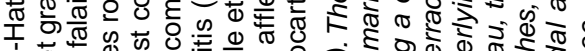

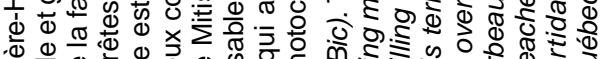

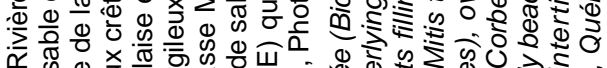

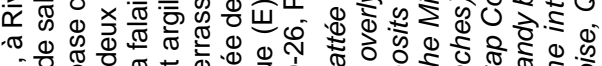

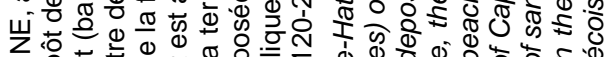

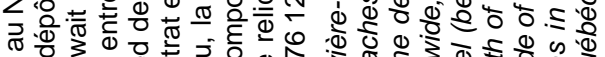

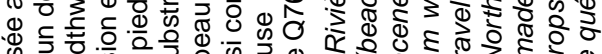
क人

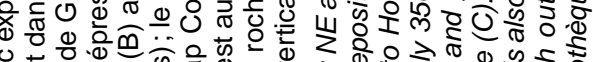

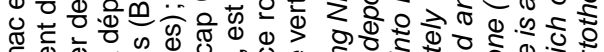

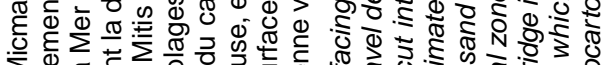

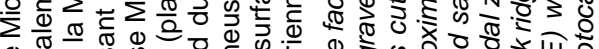

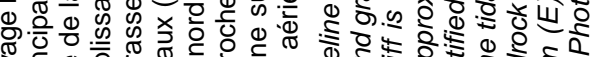

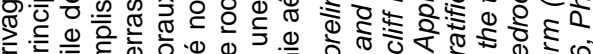

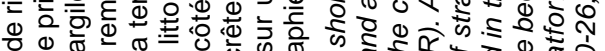
ब.

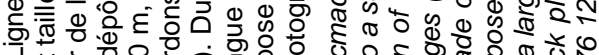

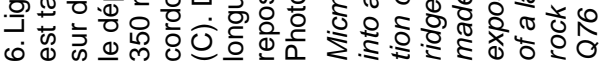

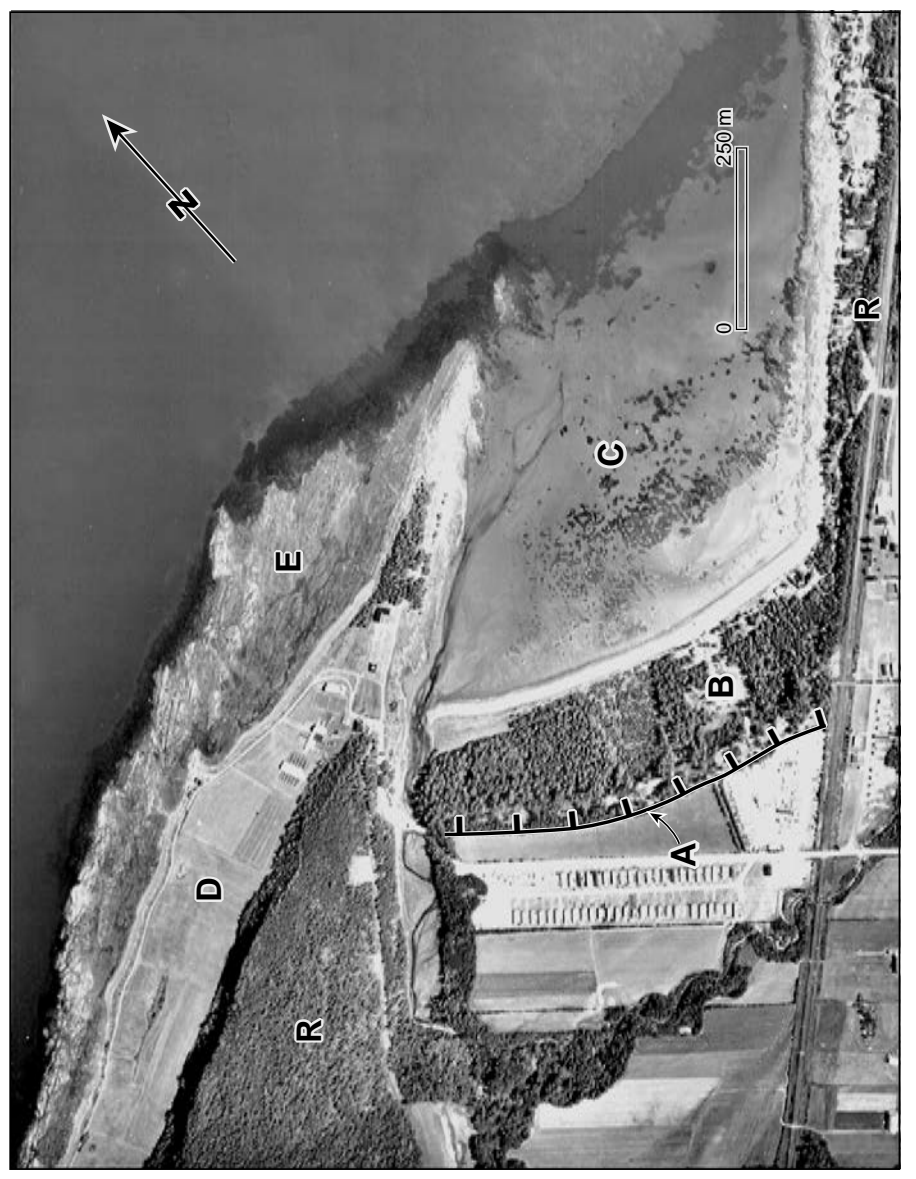




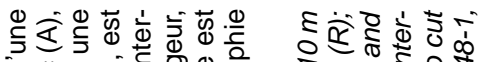

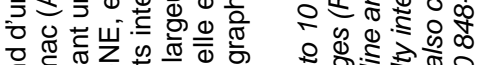

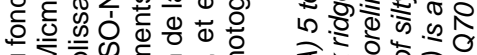

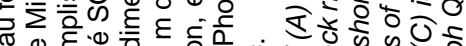

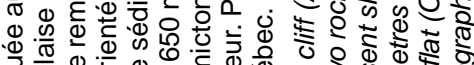

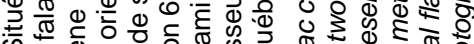

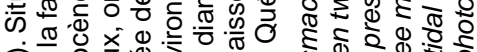

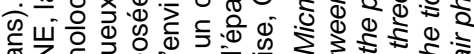
ब.

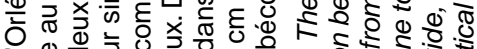

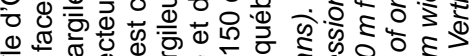
政 कo

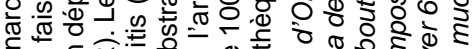

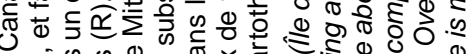

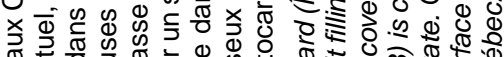
ब记 \% $\frac{\pi}{0}$.

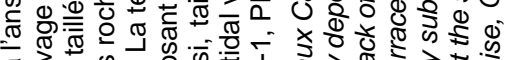

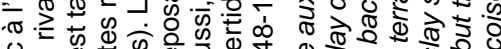

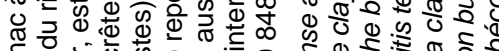

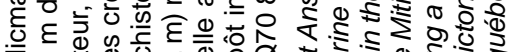

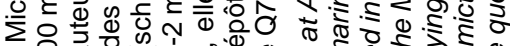
ब⿺辶寸 『ิ ब

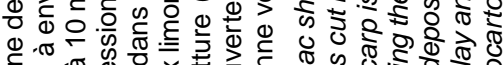

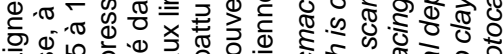

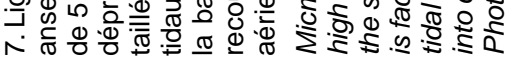

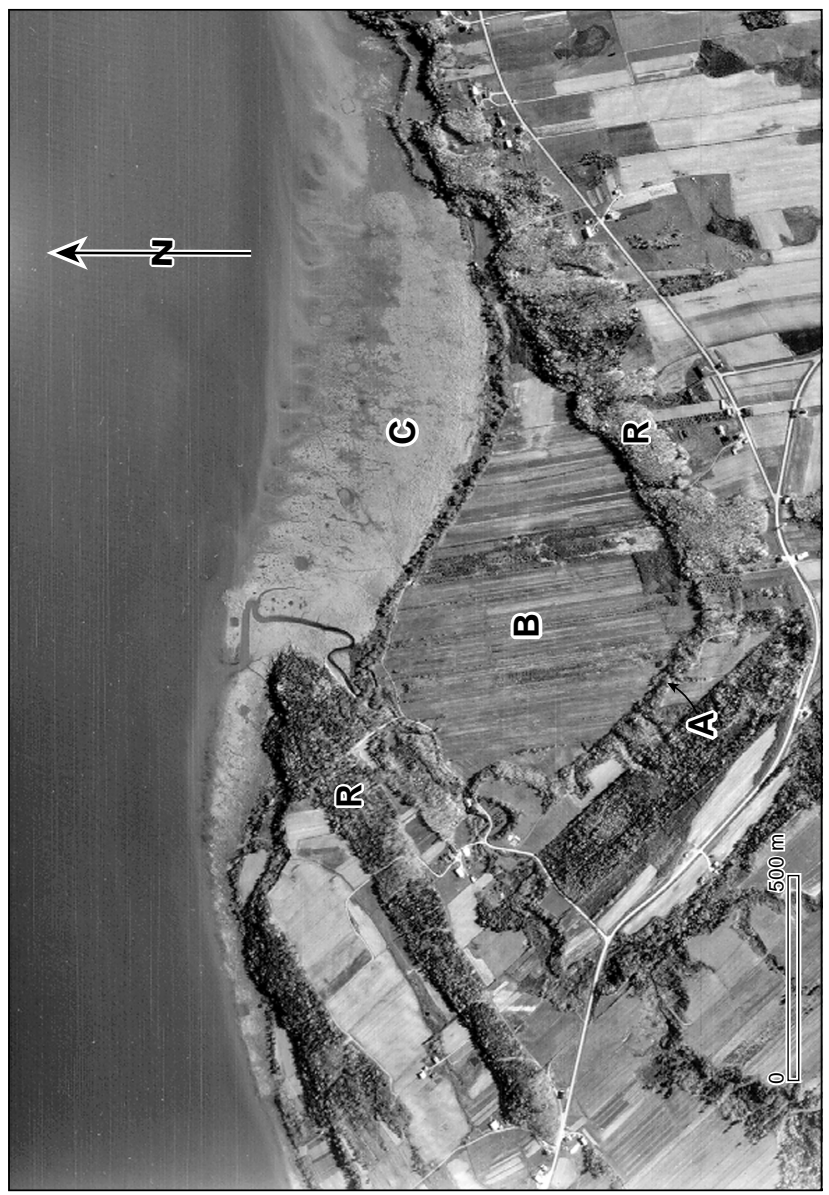

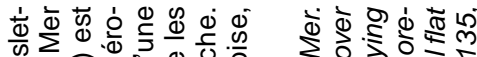

品

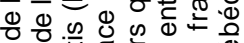

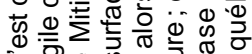
西完出

vi

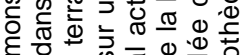

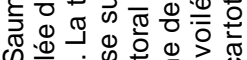

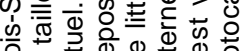

응

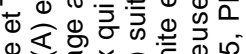

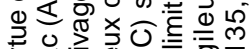

证

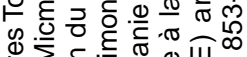

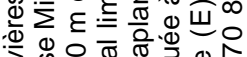

$\geq .08 \frac{\pi}{0} \pi$.

\%

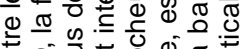

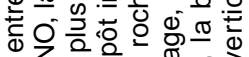

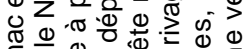

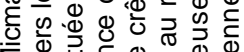

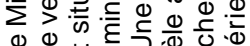

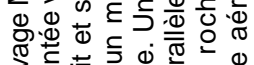

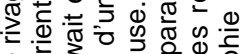

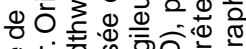

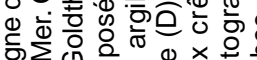

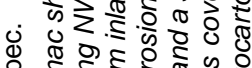

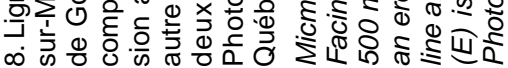

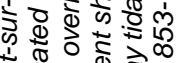

这 0

क. क⿺辶万人

0 o 8 o

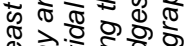

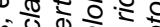

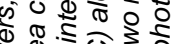

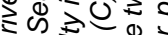

का को 0 क त

के

空

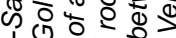

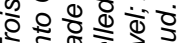

O है

की

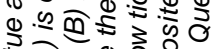

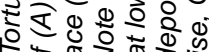

ब讨

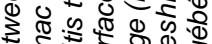

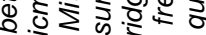

\& $\sum$ के के वे

के

每

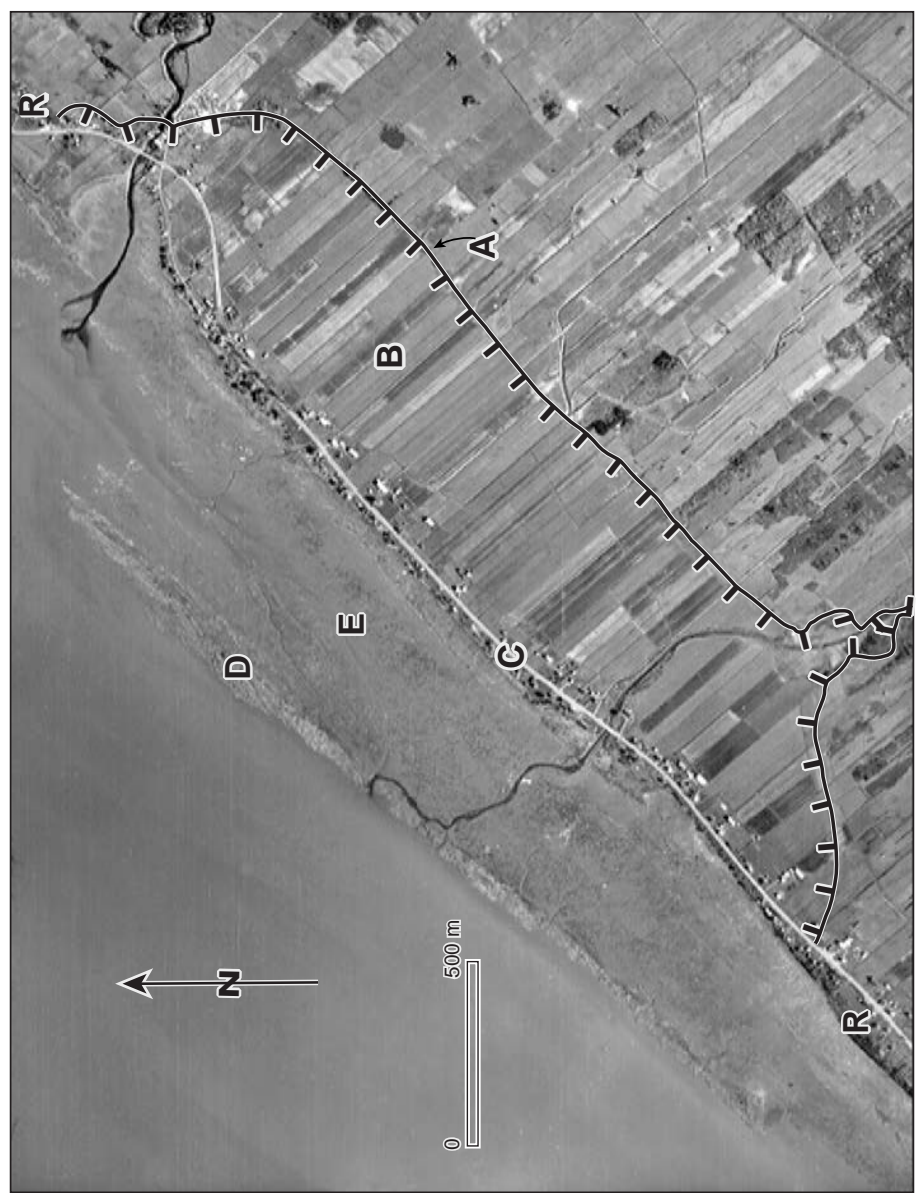



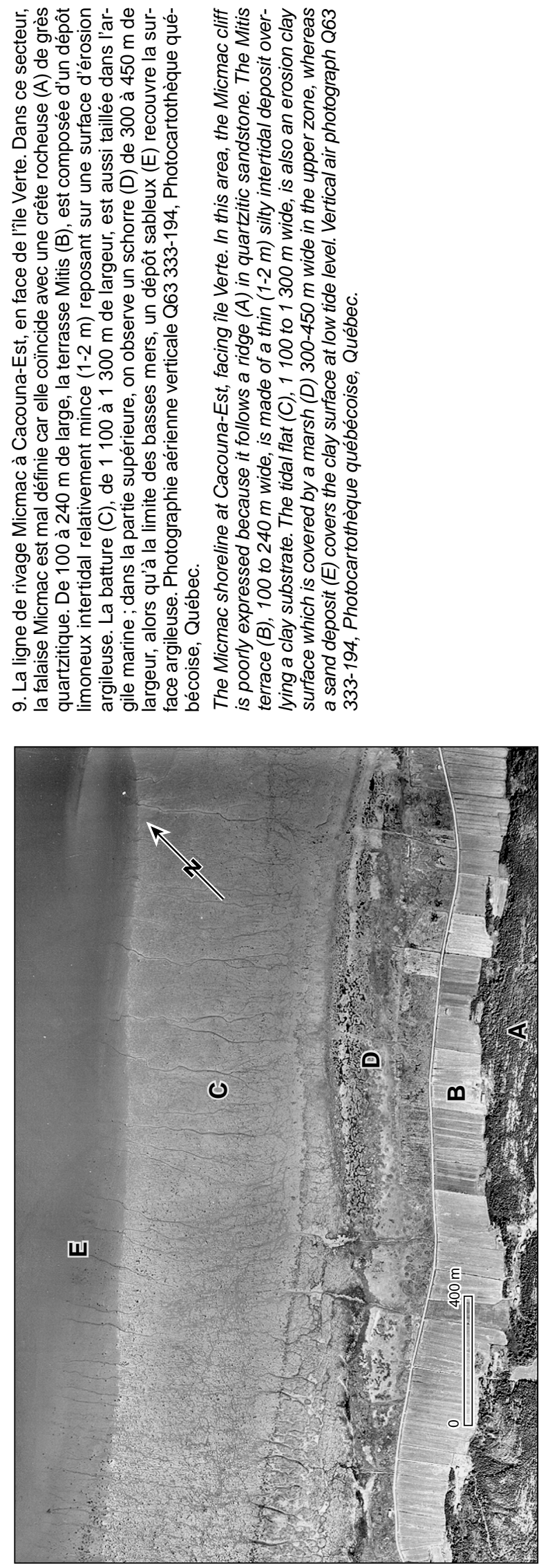
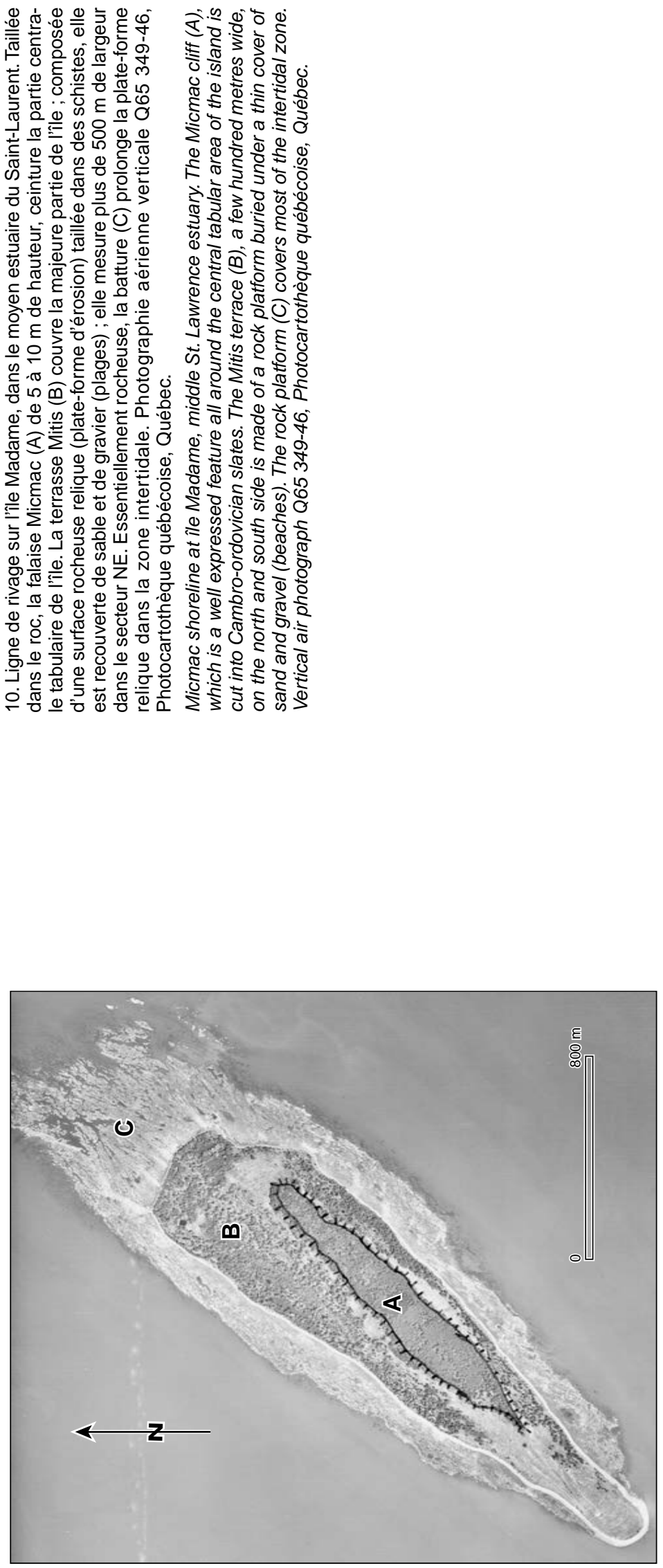